\title{
NANOTECHNOLOGIES FOR PREPARATION AND APPLICATION OF METALLIC NICKEL
}

\author{
Ivan Saldan', 2, Oksana Dobrovetska ${ }^{3}$, Oksana Makota ${ }^{3,}$.
}

https://doi.org/10.23939/chcht16.01.074

\begin{abstract}
Nanostructured nickel exhibits substantial surface area per unit volume and adjustable optical, electronic, magnetic, and biological properties, that makes nanofabricated nickel highly attractive as regards to its practical application in different fields of chemistry. Technologies on nickel nanomaterials including their simple preparation and modern application are summarized in this review.
\end{abstract}

Keywords: nanostructured nickel, metal nanofabrication, magnet, current collector, catalyst, drug delivery.

\section{Introduction}

Nickel (Ni) is $d$-metal with atomic number 28 and electron configuration $[\mathrm{Ar}] 3 \mathrm{~d}^{8} 4 \mathrm{~s}^{2}$ or $[\mathrm{Ar}] 3 \mathrm{~d}^{9} 4 \mathrm{~s}^{1}$ ([Ar] refers to the argon-like core structure) since they are very close by energy. Experimental data suggests $3 d^{8} 4 s^{2}$ energy level as the lowest energy state for $\mathrm{Ni}$ atom, though each of these two configurations splits into several energy levels due to fine structure, and the two sets of energy levels overlap. The average energy of states with [Ar] $3 \mathrm{~d}^{9} 4 \mathrm{~s}^{1}$ configuration is actually lower than that of [Ar] $3 \mathrm{~d}^{8} 4 \mathrm{~s}^{2}$, and quantum mechanical calculations using a relativistic Hartree-Fock approach invariably quotes the ground state configuration of $\mathrm{Ni}$ as $[\mathrm{Ar}] 3 \mathrm{~d}^{9} 4 \mathrm{~s}^{1{ }^{1,2}}$ This is the reason why $\mathrm{Ni}$ chemistry is very rich in complex compounds.

The most common oxidation state of $\mathrm{Ni}$ is $(+2)$, but values of $(0,+1$ and +3$)$ are well-known together with uncommon $(-2,-1$ and +4$) .{ }^{3}$ Among $\mathrm{Ni}^{0}$ complexes $\mathrm{Ni}(\mathrm{CO})_{4}$ and $\mathrm{Ni}(\mathrm{COD})_{2}$ are quite popular in the $\mathrm{Ni}$ purifying process and catalysis in organic chemistry, respectively. ${ }^{4}$ The feature of $\mathrm{Ni}^{+1}$ complexes is the presence of $\mathrm{Ni}-\mathrm{Ni}$ bonding (e.g., $\mathrm{NiBr}\left(\mathrm{PPh}_{3}\right)_{3}$,

\footnotetext{
${ }^{1}$ Ivan Franko National University of Lviv,

6 Kyryla and Mefodiia St., Lviv 79005, Ukraine

${ }^{2}$ Pavol Jozef Šafárik University in Košice,

2 Šrobárova St., Košice 04180, Slovak Republic

${ }^{3}$ Lviv Polytechnic National University,

12 Bandery St., Lviv 79013, Ukraine

makotaoksana@yahoo.com

(C) Saldan, I.; Dobrovetska, O.; Makota, O., 2022
}

$\mathrm{K}_{4}\left[\mathrm{Ni}_{2}(\mathrm{CN})_{6}\right]$ and $[\mathrm{NiFe}]$-hydrogenase). These compounds might be considered for hydrogen production during their oxidation process or catalysis for reversible oxidation of molecular hydrogen. ${ }^{5}$ Common salts of $\mathrm{Ni}$, such as chloride, nitrate and sulfate, dissolve in water to give green solutions of $\left[\mathrm{Ni}\left(\mathrm{H}_{2} \mathrm{O}\right)_{6}\right]^{2+}$ aqua complex. Some tetracoordinate $\mathrm{Ni}^{+2}$ complexes $\left(\right.$ e.g., $\left.\mathrm{NiCl}_{2}\left(\mathrm{PPh}_{3}\right)_{2}\right)$ exist in both tetrahedral and square planar geometries, which is the reason for paramagnetic and diamagnetic properties, respectively. Because of magnetic equilibrium and formation of octahedral $\mathrm{Ni}^{+2}$ complexes, $\mathrm{Ni}$ is in contrast with other $\mathrm{Me}^{+2}$ complexes of the heavier group 10 metals $\left(\mathrm{Pd}^{+2}\right.$ and $\left.\mathrm{Pt}^{+2}\right)$, which form only square-planar geometry. ${ }^{2}$ For $\mathrm{Ni}^{+3}$ ions it is very easy to form simple salts with fluoride $^{6}$ or oxide ions. One of the most famous compounds is $\mathrm{NiO}(\mathrm{OH})$ that is used as the cathode in many rechargeable batteries (e.g., $\mathrm{Ni}-\mathrm{Cd}, \mathrm{Ni}-\mathrm{Fe}, \mathrm{Ni}-\mathrm{H}_{2}$ and $\mathrm{Ni}-\mathrm{MH})$. Rare oxidation state for $\mathrm{Ni}(+4)$ was found in mixed cation oxides (e.g., $\mathrm{BaNiO}_{3}$ ), while that of $(-2)-$ in dilithium-nickel-olefin complexes (e.g., $\quad \mathrm{Li}_{2}[\mathrm{Ni}(1,5-$ $\left.\mathrm{COD})_{2}\right]$, where $(1,5-\mathrm{COD}=\operatorname{bis}(1,5 \text {-cyclooctadiene }))^{7}$

Undoubtedly, Ni-based compounds are very popular as catalyst for hydrogenation reactions, electrode materials for batteries, pigments and nutrient for some microorganisms and plants, etc. However, a question arises whether pure nickel may have similarly wide application. Historically, metallic Ni was considered to be corrosion-resistant, therefore, it has been used for plating iron and brass and coating chemistry equipment. However, Ni-plated objects may provoke nickel allergy (allergic contact dermatitis). Metallic $\mathrm{Ni}$ and its alloys (including Raney-type nickel) are very famous as catalysts in hydride production. Nickel foam or nickel mesh are used in gas diffusion electrodes for alkaline fuel cells. ${ }^{8}$ In some organic reactions pure $\mathrm{Ni}$ can manifest similar catalytic activities as the heavier group 10 metals, therefore, it might be considered as an effective and relatively cheaper catalyst than Pd or Pt. The most popular physical property of metallic $\mathrm{Ni}$ is magnetostriction $(-50$ ppm). ${ }^{9}$ Nickel is one of four elements (along with $\mathrm{Fe}, \mathrm{Co}$, $\mathrm{Gd})$ that are ferromagnetic at approximately room temperature. 
Despite the well-known use of metallic nickel, its behavior at the nanoscale is not systematized. This work intends to fill this gap. The present review demonstrates the prospects for preparation and application of metallic nickel at nano level. Chemical and physical properties of $\mathrm{Ni}$ nanoparticles (NiNPs) and mesoporous Ni (MPNi) together with their promising applications are discussed in detail.

\section{Chemical and Physical Approaches for Nanostructured Ni Preparation}

As a common $d$-metal, nanostructured Ni might be prepared using different approaches, including chemical and physical methods, some of which are very well known. Since NPs are kinetically unstable, they should be stabilized against aggregation into larger particles. Therefore, micelles, polymers, and coordinative ligands are frequently used as stabilizers to control NPs growth. Solution-based methods usually offer more control and reproducibility on NiNPs preparation. These include precipitation, deposition-precipitation, sol-gel, liquidliquid interface technique, hydrothermal and solvothermal syntheses, microwave-assisted processes, polyol method, template-directed synthesis, and ionic-liquid assisted methods. ${ }^{10}$ One of the most common and size controllable NiNPs preparation might be synthesis through thermal decomposition. ${ }^{11}$ The size of NiNPs was controlled using various alkylamines which act as size limiting agents, and through excess of tri-octylphosphine, which is used as the capping ligand. This was the first reported synthesis of spherical NiNPs capped with $N, N$ dimethylhexadecylamine and $N, N$-diisopropylethylamine synthesized through thermal decomposition of organometallic precursors. The choice of metal precursor, capping ligand and solvent, together with the variation of molar ratios of these components, time and temperature of the reaction system had all been shown to have an effect on particle size. Sintered MPNi containing hollow nickel fiber was successfully prepared in $1995 .^{12}$ The use of hollow fiber in traditional slurry-scraping technology obviously increased the porosity of MPNi. The porecrea- ting agents like polyvinyl butyral and polypropylene were useful for forming a small valuable opening. Nickel obtained through reduction of nickel hydroxide can accelerate the sintering process of MPNi. The nickel hydroxide was also helpful for the gasification of organic pore creating agents to some extent. Fabrication of NiNP might be categorized into two main types: ${ }^{13}$ 'bottom up' (starting from Ni atoms) methods and 'top down' (starting from bulk material) methods. Physical/chemical vapor deposition, pray/flame pyrolysis, biological methods, and the above-mentioned solution based methods are the main 'bottom up' examples, while mechanical milling, laser ablation and sputtering are 'top down' examples.

\subsection{The Main Methods of NiNPs Preparation}

Chemical reduction of $\mathrm{Ni}^{2+}$ ions to metallic nickel was one of the first attempts to prepare NiNPs.

An approach that combines some advantages of polyol and chemical reduction routes, such as finely dispersed nickel powder with uniform shape and size of NiNPs and high reaction rate and low reaction temperature, was suggested in $2008 .{ }^{14}$ Spherical-shape NiNPs of desirable size were prepared through chemical reduction of $\mathrm{NiCl}_{2} \cdot 6 \mathrm{H}_{2} \mathrm{O}$ in ethylene glycol with hydrazine hydrate in the conditions of various concentrations of polyvinylpyrrolidone (PVP) as stabilizing agent. It was found that the average diameter of resultant nickel nanoparticles decreased significantly with increase of PVP content. Pure NiNPs with the size of $(\sim 50-100 \mathrm{~nm})$ were successfully prepared when the ratio between Ni precursor and stabilizing agent was controlled, which essentially prevented the aggregation and growth of NiNPs. The reaction mechanism was a two-stage one:

$$
\begin{aligned}
& \mathrm{NiCl}_{2}+2 \mathrm{NaOH} \rightarrow \mathrm{Ni}(\mathrm{OH})_{2}+2 \mathrm{NaCl} \\
& \mathrm{Ni}(\mathrm{OH})_{2}+1 / 2 \mathrm{~N}_{2} \mathrm{H}_{4} \rightarrow \mathrm{Ni}+1 / 2 \mathrm{~N}_{2}+2 \mathrm{H}_{2} \mathrm{O}
\end{aligned}
$$

The first stage was proposed as a homogeneous nucleation process to form $\mathrm{Ni}(\mathrm{OH})_{2}$; the second heterogeneous process that was chemical reduction of $\mathrm{Ni}(\mathrm{OH})_{2}$ powder on the surface of liquid $\mathrm{N}_{2} \mathrm{H}_{4}$, hence the formation of NiNPs (Fig. 1).

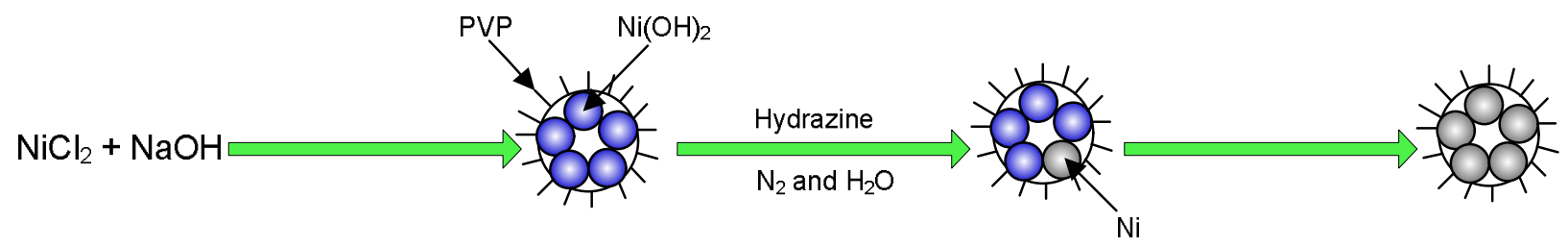

Fig. 1. The scheme of $\mathrm{NiCl}_{2} \cdot 6 \mathrm{H}_{2} \mathrm{O}$ chemical reduction in ethylene glycol with hydrazine hydrate during stabilization effect obtained from polyvinylpyrrolidone. Adapted with permission. ${ }^{14}$ Copyright (C) 2008 The Nonferrous Metals Society of China. Published by Elsevier Ltd. All rights reserved 
A similar synthetic route for the preparation of NiNPs through hydrazine reduction without any other protective agent was developed in. ${ }^{15}$ The XRD pattern confirmed that the final product was metallic nickel with the face-centered cubic (fcc) structure. It was concluded that during the formation of monodispersed NiNPs initial concentration of $\mathrm{Ni}^{2+}$ ions might be responsible for the well-dispersed nickel powder without particle agglomeration as well the number and size of NiNPs. ${ }^{15}$ The value of $0.111 \mathrm{M}$ was found as adequate precursor concentration. The average particle diameter decreased when the ratio of $\left[\mathrm{N}_{2} \mathrm{H}_{5} \mathrm{OH}\right] /\left[\mathrm{NiCl}_{2}\right]$ was increased between 2.5 and 5 and remained almost constant when the ratio was above 5 . The total process of $\mathrm{Ni}^{2+}$ ions reduction was described with chemical reactions:

$$
\begin{aligned}
& \mathrm{Ni}^{2+}+6 \mathrm{C}_{2} \mathrm{H}_{5} \mathrm{OH} \rightarrow\left[\mathrm{Ni}^{2}\left(\mathrm{C}_{2} \mathrm{H}_{5} \mathrm{OH}\right)_{6}\right]^{2+} \\
& {\left[\mathrm{Ni}_{2}\left(\mathrm{C}_{2} \mathrm{H}_{5} \mathrm{OH}\right)_{6}\right]^{2+}+m \mathrm{~N}_{2} \mathrm{H}_{4} \rightarrow } \\
\rightarrow & 6 \mathrm{C}_{2} \mathrm{H}_{5} \mathrm{OH}+\left[\mathrm{Ni}\left(\mathrm{N}_{2} \mathrm{H}_{4}\right) m\right]^{2+} \quad(m=2 ; 3)
\end{aligned}
$$

$\left[\mathrm{Ni}\left(\mathrm{N}_{2} \mathrm{H}_{4}\right) m\right]^{2+}+2 \mathrm{OH}^{-} \rightarrow \mathrm{Ni}(\mathrm{OH})_{2}+m \mathrm{~N}_{2} \mathrm{H}_{4}$

Initially $\left[\mathrm{Ni}\left(\mathrm{C}_{2} \mathrm{H}_{5} \mathrm{OH}\right)_{6}\right]^{2+}$ and then $\left[\mathrm{Ni}_{(}\left(\mathrm{N}_{2} \mathrm{H}_{4}\right) m\right]^{2+}$ complexes were formed. When nickel hydroxide was produced by reaction (5), pure nickel might appear according to reaction (2).

Another profound example of $\mathrm{Ni}^{2+}$ ions chemical reduction was made. ${ }^{16}$ NiNPs with narrow size distribution was synthesized in aqueous solutions including $\left[\mathrm{Ni}\left(\mathrm{N}_{2} \mathrm{H}_{4}\right)_{m}\right] \mathrm{Cl}_{2}$ or $\left[\mathrm{Ni}\left(\mathrm{N}_{2} \mathrm{H}_{4}\right)_{m}\right] \mathrm{SO}_{4}$ complexes. It was noticed that particle preparation with the size $<100 \mathrm{~nm}$ in aqueous solutions was not an easy process without novel metals as catalyst nuclei, and nickel hydrazine complexes had low solubility and might be easily deposited as salts. Therefore, ultrasonication and heat treatment of the precursor solution was actively applied during NiNPs synthesis. Through increase in the ultrasonication time till $60 \mathrm{~min}$ NiNPs with the average particle size of $\sim 40 \mathrm{~nm}$ were prepared.

Reduction of nickel chloride or nitrate aqueous solutions with $\mathrm{N}_{2} \mathrm{H}_{4}$ alkaline solution in the presence of cationic cetyltrimethyl bromide (CTAB) or anionic sodium dodecylsulphosuccinate (AOT) surfactants provided formation of NiNPs with the average size of $2.6-3.3 \mathrm{~nm}$ and $1.0-5.4 \mathrm{~nm}$, respectively. ${ }^{17} \mathrm{~A}$ series of colloidal NiNPs solutions was prepared through a microemulsion method using $\mathrm{NiCl}_{2} \cdot 6 \mathrm{H}_{2} \mathrm{O} / \mathrm{Ni}\left(\mathrm{NO}_{3}\right)_{2}$ as metal precursors. Microemulsion approach was studied in detail in order to optimize operating parameters in practice. To synthesize NiNPs microemulsion solutions were mixed and heated up to $353 \mathrm{~K}$ using CTAB or AOT as capping agents and $n$-octane and $n$-butanol as organic oils.

Without any surfactant NiNPs with the average size of $\sim 25 \mathrm{~nm}$ were synthesized by a facile method through reduction of the triangular $\mathrm{Ni}\left(\mathrm{HCO}_{3}\right)_{2}$ nanosheets with hydrogen. ${ }^{18}$ The facile method for the synthesis of single crystalline NiNPs supported on carbon nanotubes (CNTs) was suggested by Cheng and co-workers. ${ }^{19}$ The oxidation of CNTs with nitric acid caused its surface accessibility to $\mathrm{Ni}^{2+}$ ions that might be reduced with CNTs under inert atmosphere at elevated temperature.

Along with such reducing agents, $\mathrm{NaBH}_{4}$ was also often used for chemical reduction of $\mathrm{Ni}^{2+}$ ions. Comparing to the approach with $\mathrm{N}_{2} \mathrm{H}_{4}$, the usage of $\mathrm{NaBH}_{4}$ did not result in such a high-purity product, although it was recognized as a simple and industrial way to synthesize NiNPs. For example, in the thermodynamically unstable emulsion system, NiNPs were fabricated through chemical reduction of $\mathrm{NiSO}_{4}$ with $\mathrm{NaBH}_{4}{ }^{20}{ }^{2}$ The average size of NiNPs was related to emulsion composition, concentrations of water and surfactant, and reaction time. It was confirmed experimentally that with the increase of water-to-surfactant molar ratio $(R)$, emulsion droplet, and reaction time, the average size of NiNPs became larger and their distribution started to be non-uniform. When $R$ value was 9.5, the particle size reached the value of about $20 \mathrm{~nm}$

One of the promising NiNPs preparations might also be solgel process that is widely used today in the preparation of other metallic NPs. The $\mathrm{Ni}^{2+}$ ions were coordinated with chelating agents of citric acid (CA) and ethylene diamine tetraacetic acid (EDTA) in the aqueous solution. $^{21}$ Then the solutions were dried at $383 \mathrm{~K}$, resulting in the development of sol and gel. Heating treatments of dried gel were then carried out, with the protection of $\mathrm{N}_{2}$ atmosphere to prepare NiNPs, within the temperature range of 623-823 K. Obtained NiNPs with fcc structure had the average sizes of $15-30 \mathrm{~nm}$. Similar NiNPs were prepared with a one-pot reaction that involved nickel(II) acetylacetonate $\mathrm{Ni}(\mathrm{acac})_{2}$ reduction in oleylamine in the presence of trioctylphosphine (TOP) and 1,2-hexadecanediol. ${ }^{22}$ The reaction time and the temperature, as well the concentration of capping agent and precursor, were responsible for particle size control. Obtained NiNPs had a dominant hexagonal close-packed (hcp) symmetry, although local fcc packing was also present. An aerosol method involving metal vapor condensation in an inert gas flow was used to prepare NiNPs with the size of $15-200 \mathrm{~nm}^{23}$ A direct current electric field applied to the condensation zone can be used to control the extent of oxidation and the average size of the obtained NiNPs.

Because of different NiNPs applications, special support to introduce nanostructured nickel might be recommended. This feature quite often imposes additional problems, limiting the widespread use of various NiNPs fabrications. Since mesoporous materials based on MCM41 series are viable hosts for the controlled synthesis of 
metal NPs, aluminosilicate with the MCM-41 structure (ALMCM-41) was used as substrate for NiNPs in $1999 .^{24}$ Because of the use of ALMCM-41 substrate, ion exchange was used to introduce $\mathrm{Ni}^{2+}$ ions. Subsequent treatment of the exchange product with a reducing agent resulted in a narrow size distribution of NiNPs that demonstrated super paramagnetism, while utilizing the host pore larger magnetic NPs might be grown. Recently $\mathrm{SiO}_{2}$ microsphere supported NiNPs, which did not sinter during heat treatment at $1073 \mathrm{~K}$ for $3 \mathrm{~h}$, were successfully produced. $^{25}$ Obtained NiNPs were deposited on the surface of $\mathrm{SiO}_{2}$ microspheres through collision into the NPs with the microspheres previously heated in a gasphase reactor. It was found experimentally that $\mathrm{SiO}_{2}$ microspheres had to be heated above $1046 \mathrm{~K}$ before the collision to suppress NiNPs sintering, and their content and size could be regulated by varying the evaporation temperature of $\mathrm{NiCl}_{2}$ and the flow rate of $\mathrm{N}_{2}$ gas carrying $\mathrm{NiCl}_{2}$ vapor. Highly ordered $\mathrm{TiO}_{2}$ nanotube arrays fabricated by anodization were employed as substrate and loaded with NiNPs ( 20-80 nm) using pulse electrodeposition (PED) technique. ${ }^{26}$ The influence of PED parameters on the morphology, density, and size of NiNPs was researched. A progressive decrease of the particle size was observed with increasing current off-time ( $\left.\tau_{\text {off }}\right)$ at constant amplitude and pulse time $\left(\tau_{\text {on }}\right)$, while particle growth appeared at the increase in the deposition time at constant $\tau_{\text {off }}$ value, amplitude and $\tau_{\text {on }}$ value of both negative and positive current. At constant $\tau_{\text {off }}$ and $\tau_{\text {on }}$ values, the particle size decreased asymptotically with increasing amplitude of both negative and positive current. Another example of NiNPs on $\mathrm{TiO}_{2}$ might be atomic layer deposition (ALD) using $\mathrm{Ni}(\mathrm{II})$ dimethylamino-2-propoxide $\left(\mathrm{Ni}(\mathrm{dmap})_{2}\right)$ as precursor. $^{27}$ The growth rate of the nanoparticles on the black $\mathrm{TiO}_{2}$ nanowire arrays was $0.5 \AA$ per ALD cycle. Both pristine and black $\mathrm{TiO}_{2}$ nanowire arrays exhibited enhanced absorption within the visible light range when the ALD process was applied. Because of higher polarization that induced stronger surface plasmon resonance (SPR) of NiNPs, the maximum absorption was observed for the black $\mathrm{TiO}_{2}$ nanowire arrays, and 50 cycles of ALD exhibited the most effective photoresponse within the visible light range. The latter effect was attributed to the inter-particle interaction related to the size and loading density of NiNPs. Highly Oriented Pyrolytic Graphite (HOPG) was also used as effective substrate for NiNPs (diameter of $\sim 14 \mathrm{~nm}$ ) and continuous Ni nanowires (with $14 \mathrm{~nm}$ height and $1.5 \mathrm{pm}$ inter-wire spacing) electrodeposition. ${ }^{28}$ Obtained NiNPs were found to be attached to the HOPG surface with weak Vander Waal forces. Taking into account the calculated value of the critical force required to displace NiNPs, their manipulation was successfully carried out with magnetization or contact-mode AFM. In order to modify NiNPs with polymer shells, a surface-initiated atom transfer radical polymerization (si-ATRP) technique was successfully employed. $^{29}$ Various kinds of polymers including poly(methyl methacrylate) (PMMA) and poly(n-isopropylacrylamide) (PNIPAM) were grafted from the immobilized initiators, which were covalently bonded to NiNPs surfaces without any aggregation through the combination of ligand exchange and condensation reactions. Because of grafted polymers, obtained NiNPs with a core-shell structure had a good dispersion and stability in solvents, exchange, and condensation reactions. An iron catalyst system offered a good control over polymerization and did not lead to any corrosion threat to NiNPs. Another example that demonstrates an effective and controllable approach to NiNPs modification with a stable organic shell might be NNPs doped pitch (NNDP). ${ }^{30}$ It was prepared using the detonation of a Ni-containing explosive during the thermal polycondensation of ethylene bottom oil. NNDP can be spun into fibers through modified meltelectrospinning to form NiNPs doped carbon fibers (NNDCFs) with the diameters of $2-50 \mathrm{~nm}$ after heat treatment.

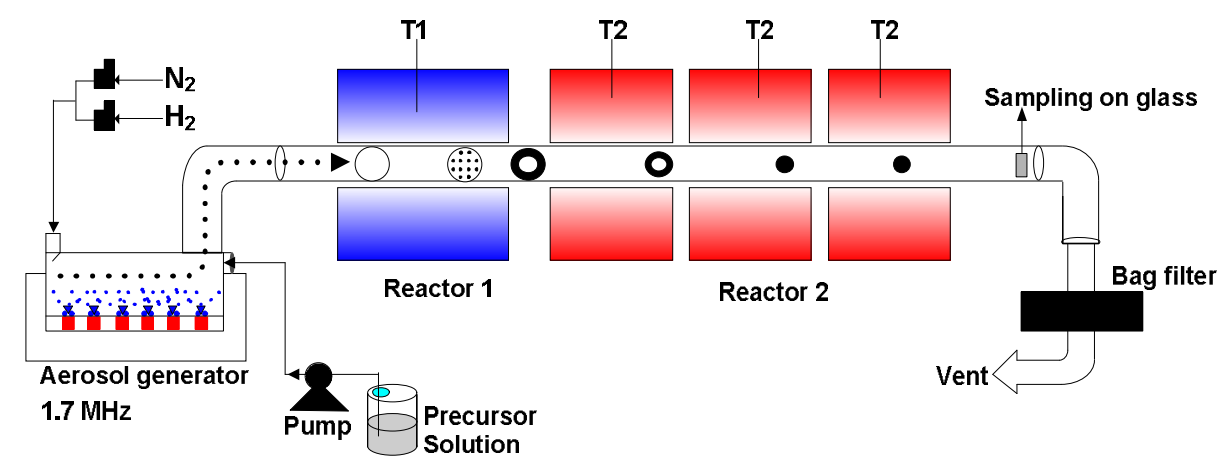

Fig. 2. The scheme of large-scale spray pyrolysis of nickel II nitrate/acetate. Adapted with permission. ${ }^{31}$ Copyright (C) 2007, Elsevier B.V. All rights reserved 


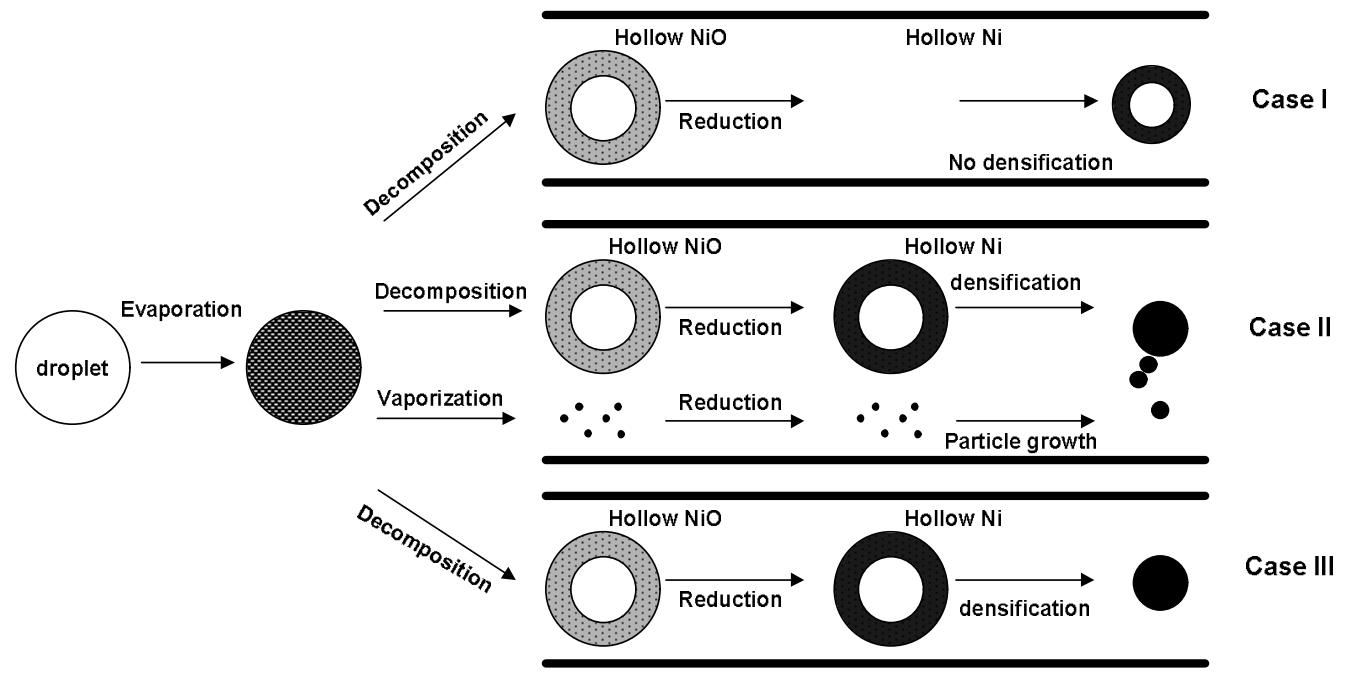

Fig. 3. Proposed mechanism of NiNP formation during the large-scale spray pyrolysis process. Adapted with permission. ${ }^{31}$ Copyright (C 2007, Elsevier B.V. All rights reserved.

Table 1. Three technological approaches to NiNP preparation through the large-scale spray pyrolysis process. Adapted with permission. ${ }^{31}$ Copyright (C) 2007, Elsevier B.V. All rights reserved

\begin{tabular}{|c|c|c|c|}
\hline Case & $T_{1}, \mathrm{~K}$ & $T_{2}, \mathrm{~K}$ & Precursor \\
\hline I & - & $<1473$ & nickel(II) nitrate \\
\hline \multirow{2}{*}{ II } & - & $\geq 1473$ & nickel(II) nitrate \\
\cline { 2 - 4 } & $\geq 1173$ & $\geq 1473$ & nickel(II) nitrate \\
\hline III & $\leq 973$ & $\geq 1473$ & nickel(II) nitrate or nickel(II) nitrate with nickel(II) acetate \\
\hline
\end{tabular}

For large NiNP preparation physical approaches are better. Spherical NiNPs were prepared by large-scale spray pyrolysis $^{31}$ (Fig. 2). The process was carried out in aqueous solution of nickel(II) nitrate/acetate at the residence time of about $3 \mathrm{~s}$ without any chemical reagents. High density of NiNPs $\left(>8.4 \mathrm{~g} / \mathrm{cm}^{3}\right)$ were obtained when reactor temperature was over $1473 \mathrm{~K}$. In case of nickel(II) nitrate, the gas-to-particle conversion resulted in the formation of NiNPs with the size $<50 \mathrm{~nm}$, while in case of nickel(II) acetate large ( 160-450 nm) NiNPs were fabricated. It was experimentally found that size and morphology control for the obtained NiNPs might be performed using temperature regulation in reactor chambers (Fig. 3 and Table 1).

Tan et al. ${ }^{32}$ successfully synthesized NiNPs by pulse laser ablation in distilled water using laser wavelengths of 1064 and $532 \mathrm{~nm}$. Experimentally it was found that the absorption peak intensities of the NiNPs increased at higher laser pulse energy and higher absorption peak was observed for the shorter laser wavelength of $532 \mathrm{~nm}$ compared to $1064 \mathrm{~nm}$. Sizes of NiNPs were almost similar for both laser wavelengths of 1064 and $532 \mathrm{~nm}$. Separate NiNPs were spherical in shape with the size of $<100 \mathrm{~nm}$ while their agglomerations were irregular in shape and several times larger.

\subsection{The MPNi Fabrication}

Almost 20 years ago porous metallic nickel was in high demand for battery, catalyst, and filter material applications, and today the demand is becoming even higher, specifically due to macro- to meso- or even microproposity of $\mathrm{Ni}$ where pore dimeters are within the range of $>50 \mathrm{~nm} ; \sim 2-50 \mathrm{~nm}$ and $<2 \mathrm{~nm}$, respectively. Traditionally such structures were prepared through sintering of fine filamentary nickel powders but often the strength of such porous structures was rather low, for example, comparing with $\mathrm{Ni}$ foams of similar density. To improve the powder particle distribution and, hence the strength of the final sintered structure, colloidal methods were applied by Zaitsev et al. ${ }^{33}$ Prior introduction of a binder dispersing $\mathrm{Ni}$ powder in water took place with further addition of dispersants that led to better separation of NiNPs, avoiding their conglomerates and improving their distribution. These colloidal techniques enhanced control of the slurry viscosity and density of the nickel porous body and promoted higher tensile strength of the prepared MPNi. Additionally, it was found that residual sulfur adversely affected the strength of the sintered nickel powder. Therefore, due to the combination of these colloidal methods and sulfur-free dispersants, the strength 
to porosity ratio of sintered MPNi was increased. In order to quantify the effect of the methods used in terms of increased uniformity of the ligament spacing and density of ligament connections, analysis of fracture surfaces was effectively applied in practice. Using sonication method synthesis of MPNi with pore diameter of $4-6 \mathrm{~nm}$ was successfully carried out with $\mathrm{Ni}(\mathrm{II})$ sulphate as precursor and cetyltrimethylammonium bromide as organic surfactant. ${ }^{34}$ The surfactant was removed with solvent extraction and calcination. The Brunauer-Emmet-Teller surface area was reported to have H2-type hysteresis for the obtained MPNi.

A series of macroporous $\mathrm{Ni}$ were fabricated through the lost carbonate sintering (LCS) process from pure Ni powder with the average particle size of $25 \mu \mathrm{m}$ and $\mathrm{K}_{2} \mathrm{CO}_{3}$ powder with particle size within the range of 250-1000 $\mu \mathrm{m}$ (Fig. 4) ${ }^{35}$ Obtained Ni foams had porosity value within the range of $0.5-0.77$. The pore diameters of macroporous $\mathrm{Ni}$ were within the range of $250-425,425$ 710 , and $710-1000 \mu \mathrm{m}$, which was predicted by previously sieved $\mathrm{K}_{2} \mathrm{CO}_{3}$ powder. Mixed $\mathrm{Ni}$ and $\mathrm{K}_{2} \mathrm{CO}_{3}$ powders were compacted by $200 \mathrm{MPa}$ and sintering at $1223 \mathrm{~K}$ for $2 \mathrm{~h}$. The microstructure of macroporous $\mathrm{Ni}$ prepared by LCS were composed of interconnected open pores with the size of used $\mathrm{K}_{2} \mathrm{CO}_{3}$ particles (Fig. 5a). For comparison of morphology, other macroporous $\mathrm{Ni}$ samples were manufactured by loose sintering and electrodeposition (Fig. 5b,c). The microstructure of macroporous $\mathrm{Ni}$, prepared by loose sintering of spherical Ni powder with the average particle size of $75 \mu \mathrm{m}$ without any additives, was composed of sintered Ni particles with pore diameters of $\sim 10 \mu \mathrm{m}$ and porosity of $\sim 0.50$ (Fig. $5 \mathrm{~b}$ ). The highest porosity value $(\sim 0.98)$ was obtained for the sample prepared by electrodeposition of $\mathrm{Ni}$ onto the polymer foam followed by the polymer substrate burn-off. The microstructure of macroporous $\mathrm{Ni}$, prepared through electrodeposition, was composed of $\mathrm{Ni}$ ligament network with polyhedron cells in the order of $500 \mu \mathrm{m}$ (Fig. 5c). Because of the lack of cell walls, the cells could not be considered as typical pores, therefore, this macroporous $\mathrm{Ni}$ can be regarded as a material with a very large pore diameter.

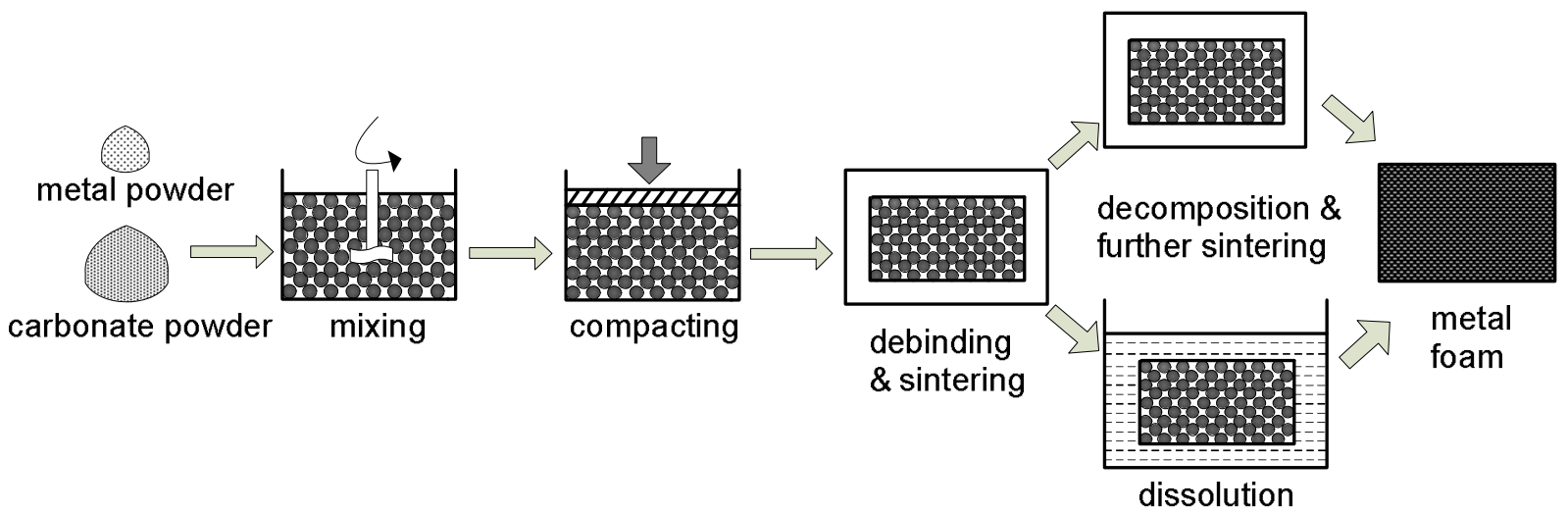

Fig. 4. The scheme of lost carbonate sintering process for manufacturing $\mathrm{Ni}$ foam. Adapted with permission. ${ }^{35}$ Copyright $\mathbb{C}$ 2019, Elsevier B.V. All rights reserved

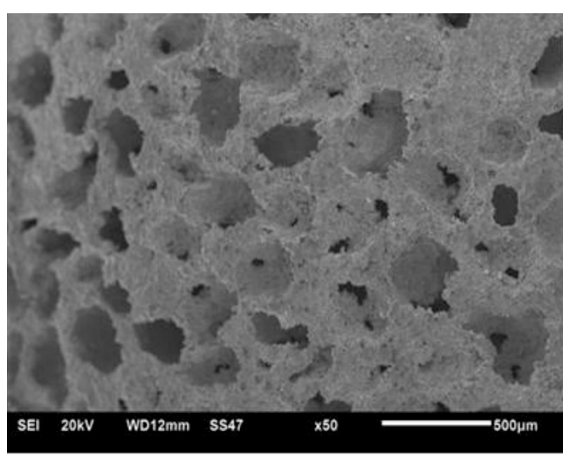

a)

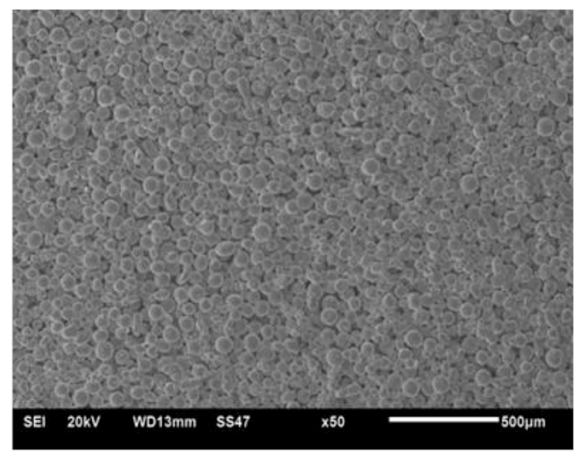

b)

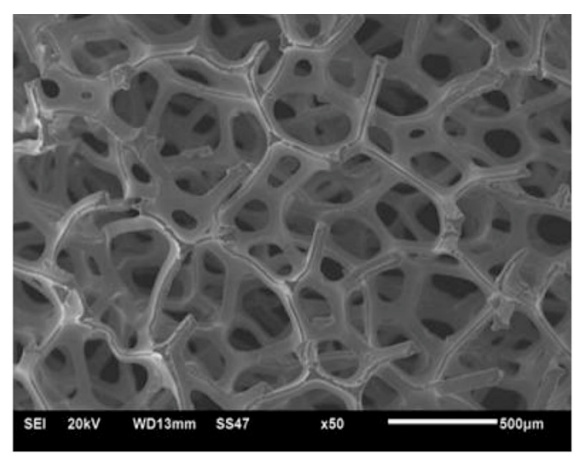

c)

Fig. 5. SEM micrographs of porous Ni samples manufactured by lost carbonate sintering (a), loose sintering (b), and electrodeposition processes (c). Reprinted with permission. ${ }^{35}$ Copyright (C) 2019, Elsevier B.V. All rights reserved 
Macroporous $\mathrm{Ni}$ wafers were prepared by a molding-decomposition-sintering method. ${ }^{36}$ The Ni oxalate nano-rods were used as precursor and decomposed at $633 \mathrm{~K}$. For technological optimization, the sintering temperature was chosen as $693,723,753$, and $783 \mathrm{~K}$ in a tubular oven filled with Ar atmosphere. At the first stage, during molding process a great deal of small pores were formed. Secondly, during $\mathrm{Ni}$ oxalate decomposition, gaseous $\mathrm{CO}_{2}$ and $\mathrm{H}_{2} \mathrm{O}$ were released and agglomerated $\mathrm{Ni}$ nanofibers with big pores were formed. This was exactly the moment when the volume of wafers became smaller and harder. At the third stage, during sintering the surface of $\mathrm{Ni}$ nanofibers started melting and bonding to each other. Finally, Ni fibers became shorter and thicker, that resulted in smaller pore diameters and appearance of $\mathrm{Ni}$ blocks. Obtained Ni wafers showed the morphology of a porous structure and had fcc crystal structure. The structure of macroporous nickel wafers was irregular, with the pore diameter of $100-1000 \mathrm{~nm}$ and fiber-like wall diameter of $100-300 \mathrm{~nm}$. Mohamed et al. ${ }^{37}$ showed that porous $\mathrm{Ni}$ was fabricated by compacting $\mathrm{Ni}$ powder followed by sintering in vacuum at $393 \mathrm{~K}$ for $2 \mathrm{~h}$. The average oxidation rate for porous and cast $\mathrm{Ni}$ samples was initially rapid and then decreased gradually to become linear. It was experimentally found that linear oxidation kinetics and the formation of porous non-adherent duplex oxide scales on inhomogeneous $\mathrm{Ni}$ substrates might be possible. Addition of new $\mathrm{NiO}$ layers occurred at the scale/metal interface due to the thermodynamically possible reaction between $\mathrm{Ni}$ and molecular oxygen migrating inwardly.

Similarly to NiNPs, MPNi were also used in composites but often as substrate. $\mathrm{Wu}$ and co-workers ${ }^{38}$ presented the production of MPNi with Pd surface decoration by electrochemical methods. It was experimentally demonstrated that, by taking advantage of the formation of a passive Ni oxide film, MPNi could be prepared through selective electrochemical dissolution of the more noble $\mathrm{Cu}$ from electrodeposited $\mathrm{Ni}-\mathrm{Cu}$ alloys (Fig. 6). First, a bimetallic Ni-Cu film deposited on the Ni foam support was prepared through electrodeposition process and then MPNi film with a nanotube-like structure was obtained through selective electrochemical dissolution of the more noble $\mathrm{Cu}$. Eventually, $\mathrm{Pd}$ deposition on the surface of MPNi was harvested by a galvanic replacement reaction between MPNi and $\mathrm{K}_{2} \mathrm{PdCl}_{4}$ solution.

A nanostructured MPNi-based composite was prepared by El Naggar et al. ${ }^{39}$ The material obtained was Ni-B based alloy supported by nylon fiber. The MPNi preparation involved electroless plating (ELP) of Ni alloy particles using template approach, i.e., metal particle deposition within the pores of the template. Performance of the prepared composite was evaluated in terms of acquired hydrogen recovery. High concentration as well as the good distribution of nickel deposits within the composite structure was the reason for good reliability and catalytic performance in the process of hydrogen separation.

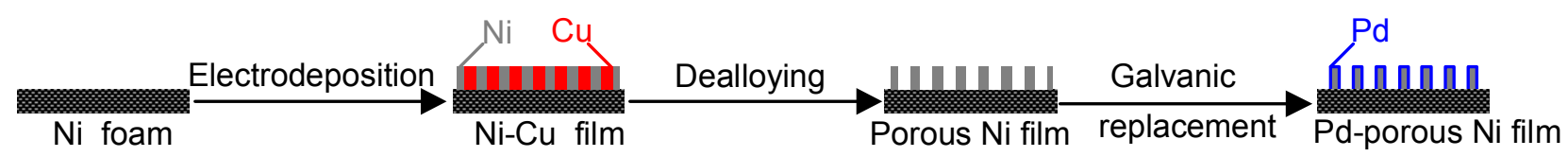

Fig. 6. Schematic diagram of Pd-porous $\mathrm{Ni} / \mathrm{Ni}$ foam preparation by a combination of dealloying and galvanic replacement methods. Adapted with permission. ${ }^{38}$ Copyright (C) 2019, Elsevier B.V. All rights reserved

\section{Properties of Nanostructured Ni}

In contrast to bulk metallic $\mathrm{Ni}$, nanostructured $\mathrm{Ni}$ might exhibit a huge surface area per unit volume and tunable optical, electronic, magnetic, and biological properties. NiNPs with different sizes, shapes, and surface characteristics can be prepared. Conditions of NiNPs or MPNi fabrications (e.g., reaction temperature and time, capping ligands and solvent, etc.) promote their specific properties. For example, (111) oriented single-crystalline NiNPs, produced by solid-state dewetting, might exhibit an ultrahigh compressive strength (up to $34 \mathrm{GPa}$ ) unprecedented for metallic materials. ${ }^{40}$ This strength matches available estimates of $\mathrm{Ni}$ theoretical strength supported by molecular dynamics (MD) simulations that closely mimic the experimental conditions. Cu-NiNPs were found as additive that improved load-carrying capacity and tribological properties of liquid paraffin. ${ }^{41}$ This might be attributed to the rolling effect of the agglomerate $\mathrm{Cu}-\mathrm{Ni}$ nanocores during sliding and formation of a boundary lubricate film. The critical domain for Ni was reported to be approximately $55 \mathrm{~nm}^{42}$ However, two years later, $16 \mathrm{~nm}$ NiNPs with hcp were synthesized, which demonstrated ferromagnetism and a coercivity of 8 Oe at $300 \mathrm{~K}^{43}$ This indicates that the particles with diameters below the theoretical single domain boundary can still exhibit ferromagnetism. Therefore, the size of NiNPs alone does not determine whether the particles are single- or multi-domain ones by nature. In the $20^{\text {th }}$ century bulk $\mathrm{Ni}$ was recognized as catalyst for some polymer reactions involving hydrogenation and condensation and today there are a lot 
of examples of electro-, photo-, and chemical catalytic reactions on a metallic $\mathrm{Ni}$ or $\mathrm{Ni}$ modified surface. Catalytic activity of MPNi regarding molecular hydrogen was found out many years ago, although the mechanism of $\mathrm{H}^{+}$and $\mathrm{H}^{-}$ions formation on Ni surface is not completely clear. Recently the mechanism to produce negative and positive ions has been studied using constrained DFT. ${ }^{44}$ It has been found that when hydrogen atoms leave Ni surface from top sites, the charge of hydrogen is negative, while at bridge sites or center sites with lower electron density atoms of hydrogen mainly get a positive charge. These peculiarities of nanostructured $\mathrm{Ni}$ show intrinsic mechanical, magnetic, and catalytic properties.

\subsection{Mechanical Properties of Ni Nanomaterials}

It is well-known that deformation mechanisms change once the sample size is reduced in at least one dimension into the micrometer range. Therefore, a natural question is to ask whether further downscaling can produce objects reaching the theoretical strength of the material. In ductile metals and alloys the latter is defined as the resolved shear stress in the primary glide plane, that causes homogeneous sliding of two neighboring atomic planes past each other. ${ }^{40}$ An alternate definition relates the theoretical strength to the shear stress required for homogeneous, barrier-free nucleation of a dislocation loop in a perfect crystal. According to different estimates, the theoretical shear strength varies from $G / 30$ to $G / 8$, where $G$ is the shear modulus of the material. In nanoindentation

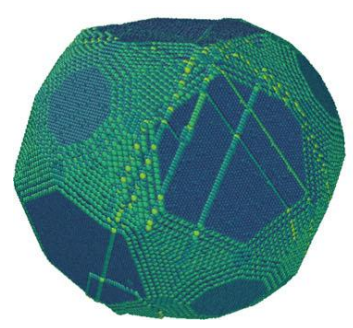

a)

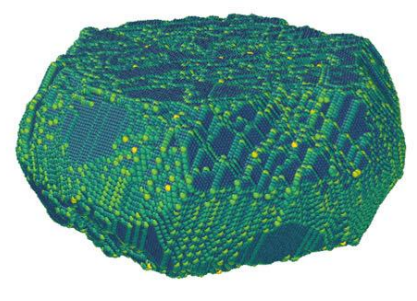

b) tests on well-annealed metallic single crystals, abrupt displacement bursts are usually explained by homogeneous dislocation nucleation when the local shear stress reaches the theoretical strength. This nucleation process is usually discussed in terms of the Hertz elastic contact theory which predicts that the maximum shear stress is reached at a point some distance away from the contact. In a well-annealed single crystal, chances are high that this point is located in a defect-free region and thus a dislocation can only nucleate homogeneously. This argument also applies to spherical metallic nanoparticles tested with a flat punch. Experimental findings reported by Sharma et al. ${ }^{40}$ were supported by MD simulations that closely reproduce the experimental conditions and provide additional insights into the dislocation mechanisms increasing the particle strength. Examination of MD snapshots revealed that compressive stress dropped immediately after the nucleation of the first dislocation and its passage through the particle. This passage triggered surface nucleation and subsequent glide of new dislocations, their multiplication, and eventually a dislocation avalanche resulting in a large increment of strain. In other words, the nanoparticle strength is totally controlled by the nucleation of the first dislocation. Accumulation of strain was accompanied by the development of an increasing number of dislocation slip traces on the NiNPs surface. Eventually, the particle with the diameter of $25 \mathrm{~nm}$ was compressed to a pancake-like shape with fractured fringes similar to those in the experimental particles (Fig. 7c).

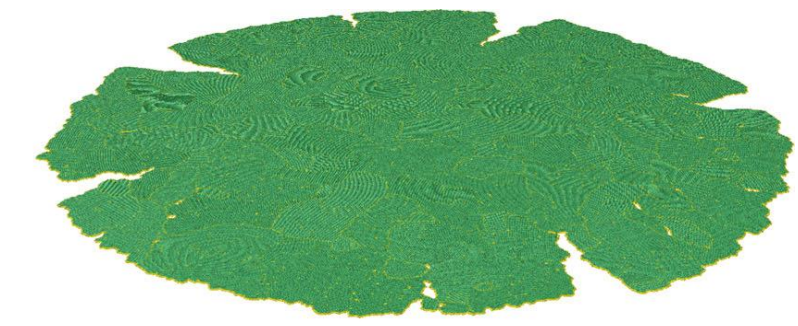

c)

Fig. 7. The NiNPs shapes at different stages of simulated compression tests: after the first burst of compressive strain with dislocation slip traces on the surface (a), later stage of compression (b) and the final shape (c). Reprinted with permission. ${ }^{40}$ Copyright (C) 2018, Nature Publishing Group. All rights reserved.

Careful examination of MD snapshots revealed that, at high stress levels, the stress components thermally fluctuated inside the particle, occasionally creating localized states, so called 'hot spots', with significant atomic displacements relative to the neighbors. Such fluctuations favored loop development and gave rise to multiple nucleation attempts, until one of them turned out successful and created a dislocation loop capable of further growth. It was shown that 'hot spots' tend to be localized in certain zones inside the particle. However, such zones did not coincide with the regions of the highest resolved shear stress, hydrostatic stress, von Mises stress, or any other stress measures. However, they seemed to correlate with the regions of the largest resolved shear 
stress gradient. Tentatively, hot zones could be linked to phonon behavior at finite temperatures, for example, to the focusing of phonons reflected from the surfaces of smooth corners acting like parabolic mirrors. Experimental and theoretical measurements performed by Sharma et al..$^{40}$ demonstrated that theoretical strength of NiNPs can be readily achieved through elimination of all dislocations and creation of optimal shapes with rounded corners and edges between crystallographic facets. It was concluded that single-crystalline, faceted, and dislocationfree Ni samples with more complex shapes (nanowires or nanoframes) might exhibit similar high strength. These nanostructured $\mathrm{Ni}$ can find important applications in catalysis, electric conductivity or as an additive to lubricants (ball-bearing effect).

Tribological properties of $\mathrm{Cu}-\mathrm{Ni}$ bimetallic NPs in liquid paraffin were evaluated with an MSR-10A four-ball friction and wear tester (Fig. 8). ${ }^{41}$ The friction and wear tests were conducted at the rotary speed of $1450 \mathrm{rpm}$, an ambient temperature of about $298 \mathrm{~K}$, an applied load of $196 \mathrm{~N}$ or $392 \mathrm{~N}$, and a sliding duration of $60 \min (196 \mathrm{~N})$ or $30 \mathrm{~min}(392 \mathrm{~N}) .^{14}$ The friction and wear tests were repeated three times under each preset condition to minimize data scattering. At the end of each test the wear scar diameter (WSD) of the three lower balls was measured with an optical microscope with the accuracy of $0.01 \mathrm{~mm}$. The average wear scar diameter of the three lower balls was calculated and morphology of the worn surfaces as well as composition and chemical states of typical elements on the worn surfaces were analyzed.

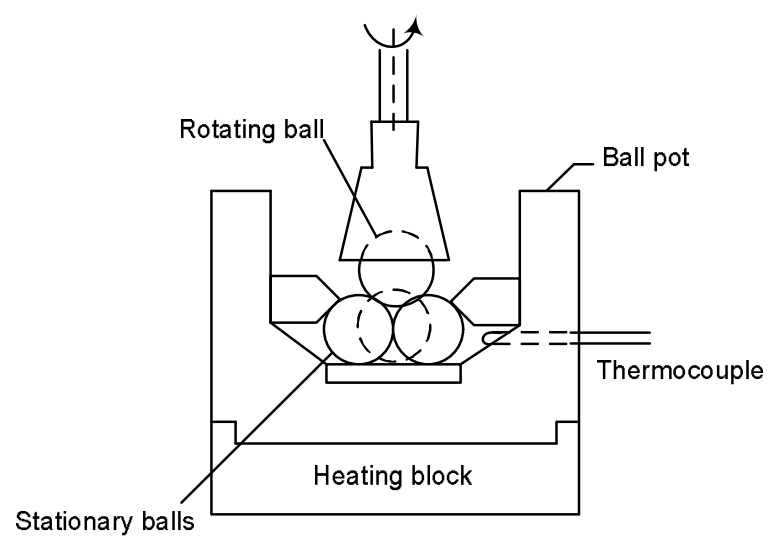

Fig. 8. Schematic diagram of the four-ball fraction and wear tester. Adapted with permission. ${ }^{41}$ Copyright (C) 2017, Elsevier B.V. All rights reserved.

It was found that the dodecanethiol ligand was able to effectively increase the dispersibility of bimetallic $\mathrm{Cu}-$ $\mathrm{Ni}$ NPs in apolar solvents and prevent them from oxidation. Moreover, $\mathrm{Cu}-\mathrm{Ni}$ NPs significantly improved the load-carrying capacity and tribological properties of liquid paraffin. This might be attributed to the rolling effect of agglomerate $\mathrm{Cu}-\mathrm{Ni}$ nanocores released by $\mathrm{Cu}-\mathrm{Ni}$ NPs during sliding and formation of a boundary lubricating film containing tribo-chemical reaction products such as iron oxides and iron sulfate.

Porous $\mathrm{Ni}$ foam was applied to fabricate a triboelectric nanogenerator (TENG) that could harness ambient vibration and footfalls, which are the most common and available mechanical motions for powering electronics. ${ }^{45}$ Constructed TENG consisted of two substrates, electrodes, triboelectric materials, and springs (Fig. 9a). A sheet of porous Ni foam that played the role of the contact surface and an electrode were attached on the lower side (Fig. 9b). Porous Ni foam (SEM image in Fig. 9c) was prepared via $\mathrm{Ni}$ electroplating on the electric conductive organic template, with further elimination of the template through reductive sintering. Polymethyl methacrylate (PMMA), selected as supporting substrate, in virtue fits felicitous strength with good processing, light weight, graceful appearance, and low cost (Fig. 9d). Back electrode (aluminum foil) was fixed on the substrate and contact surface (polydimethylsiloxane (PDMS) that was directly spin-coated on PMMA). Four springs supported the two substrates leaving a narrow gap at the corners. With hybridization of both the contact-separation and sliding electrification modes of the porous $\mathrm{Ni}$ foam top inserting into flexible PDMS, constructed TENG could generate a uniform signal output at the short-circuit of $71.9 \mu \mathrm{A}$ and an open-circuit voltage up to187.8 V.

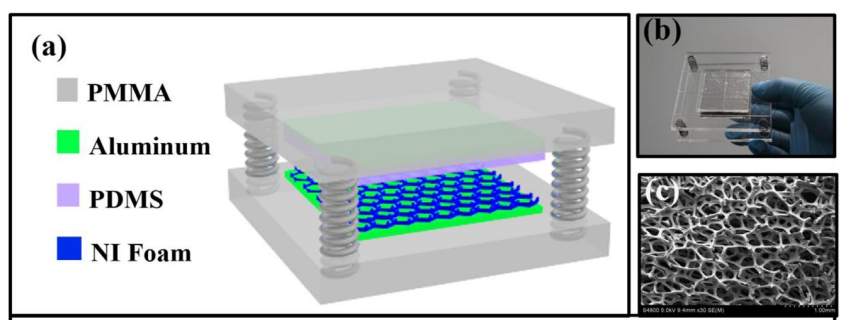

Fig. 9. The scheme (a) and photo (b) of the triboelectric nanogenerator. SEM image of porous Ni foam (c). Reprinted with permission. ${ }^{45}$ Copyright (C) 2015, Elsevier B.V. All rights reserved.

\subsection{Magnetic Properties of Ni Nanoparticles}

Studying of the magnetic properties of NiNPs has already become one of the most active research directions. In 2001 it was reported that NiNPs with the average diameter of $10 \mathrm{~nm}$ showed the behavior of a random magnet with a high field-dependent irreversibility temperature $\left(T_{\text {irr }}\right)^{46}{ }^{4}$ Separate NiNP acts as a super paramagnet and a spin glass above and below $T_{\text {irr }}$, respectively. Magnetic relaxation studies showed a clear 
logarithmic time dependence and a strongly field and temperature dependent effective barrier. The data suggested the model where the time-dependent dipole field dominated magnetic relaxation of NiNPs. In 2010 it was found that magnetic hysteresis loops of shuriken-like NiNPs (particle diameter of 100-200 nm; fcc crystal structure) illustrated ferromagnetic nature at $300 \mathrm{~K}^{47}$ This fact indicates potential application of NiNPs in magnetic storage. For NiNPs with the average diameter of $4 \mathrm{~nm}$ zero field cooled (ZFC) and field cooled (FC) magnetization versus temperature displayed magnetic interaction effect at approximately $5 \mathrm{~K}$, indicating the super paramagnetic behavior. ${ }^{48}$ Magnetic anisotropic constant was estimated to be $4.62 \cdot 10^{5} \mathrm{erg} / \mathrm{cm}^{3}$, and coercive field was $168 \mathrm{Oe}$ at $3 \mathrm{~K}^{49}$ NiNPs were synthesized in a magnetic $\mathrm{Ni}$ phthalocyanine anions matrix based on intercalation between potassium atoms and $\mathrm{Ni}$ phthalocyanine $(\mathrm{NiPc})$ at $573 \mathrm{~K}$. It was found that $\mathrm{K}_{2} \mathrm{NiPc}$ had approximately $1 \mathrm{wt} \%$ of NiNPs with the average diameter of $15 \mathrm{~nm}$ and with fcc structure. The measured values of magnetization and absorption of ferromagnetic resonance considerably predominated the magnetism which could be attributed to pure NiNPs. The results obtained indicated the presence of room temperature molecular ferromagnetism caused by anionic molecules of $\mathrm{NiPc}$, that made a significant contribution to ferromagnetic resonance. It was very interesting that at helium temperatures, along with the observed ferromagnetic resonance of pure NiNPs and anionic molecules of $\mathrm{NiPc}$, giant paramagnetism with drastic decrease in intensity with the temperature was also observed at $g=2$. This EPR signal at $g=2$ might be determined by NiPc anions and clusters of anionic molecules of NiPc, that showed disordering in mutual orientation of different NiPc molecules, with the preserved structure of each molecule. The effect of NiNPs addition on magnetic properties of polystyrene (PS) was studied by El Komy and co-workers. ${ }^{50}$ NiNPs were synthesized by reduction method and added to polystyrene as filler with different weight percentages (3, 5, 8 and $10 \mathrm{wt} \%)$ to form Ni-PS composite films. XRD measurements confirmed fcc structure of NiNPs embedded in semi crystalline PS matrix and showed that the average size of NiNPs increased with increasing Ni content from 3 to $8 \mathrm{wt} \%$ while decreased at $10 \mathrm{wt} \%$ due to dominant nucleation over aggregation process. HRTEM revealed individual NiNPs with needlelike shaped particles and their agglomerates forming dense balls with the diameter of 50-200 nm. With increasing of NiNPs the optical band gap of Ni-PS composite films decreased from 4.54 to $3.91 \mathrm{eV}$ that suggested direct effect of NiNPs on the electronic structure of the PS matrix. All samples demonstrated ferromagnetic behavior with wellpronounced magnetic hysteresis, except pure PS that showed diamagnetic behavior. The exchange bias effect at room temperature was observed and discussed for Ni-PS composite films. The value of coercivity of pure NiNPs increased from 154.13 to $185.5 \mathrm{G}$, measured in the Ni-PS composite films, while the value of room temperature exchange bias $\left(H_{\mathrm{EB}}\right)$ decreases with increasing $\mathrm{Ni}$ content from 56.5 to $21.1 \mathrm{G}$. These results suggested strong coupling between the ferromagnetic phase and the disordered surface spins in the PS matrix. Magnetic susceptibility of thin films made of NiNPs with polyvinyl alcohol and graphite was experimentally studied by Aneli et $a l^{51}$ Gradient distribution of NiNPs in the stretched direction resulted in equivalent change of magnetic properties. It was concluded that structural anisotropy was the main reason of anisotropy in magnetic properties of the composites.

A great interest in magnetic and radiative properties of porous $\mathrm{Ni}$ has recently been shown in theoretical works. For example, spectral radiative properties of porous $\mathrm{Ni}$, including wavelength-selective transmission, reflection, and absorption, were theoretically observed by Liu et al. ${ }^{52}$ The finite-difference time-domain (FDTD) method for electromagnetics was used to calculate spectral radiative properties. It was found that the absorption spectra of porous $\mathrm{Ni}$ microstructure will generate two peaks within the wavelength range of $0.2-$ $2.0 \mu \mathrm{m}$ at normal light incidence. Furthermore, the value, position and shape of the absorption peaks were dependent on the pore diameter, Ni filling height, incident angle, and light polarization. The magnetic polariton (MP) resonance could be observed clearly, which might be the crucial mechanism to estimate power absorption enhancement. Additionally, it was calculated that power absorption predominantly focused on the top surface of the porous Ni structure, especially in the region near the orifice. These theoretical results suggest future applications of porous Ni like thermophotovoltaics (TPV) and impact energy absorption.

\subsection{Catalytic Properties of Metallic Ni in Hydrogen Exchange Reactions}

Many inorganic and organic chemical reactions involve relocation of hydrogen protons, atoms, or molecules, which need to be exchanged with other ions, atoms, or radicals on the reaction route. Hydrogenation/dehydrogenation, reduction/oxidation, synthesis of organic compounds, electrochemical and fuel cells reactions are the most common types of chemical reactions involving hydrogen exchange. All these reactions may exhibit a wide spectrum of various types of reaction mechanisms and different nature of atomic interactions, where the efficiency of hydrogen relocation controls reaction rate and efficiency. Today improving the efficiency of hydrogen relocation is the main challenge for many chemical technologies where reactions with 
hydrogen transfer can be facilitated by catalysis. It is wellknown that the main role of these catalysts is to promote atomic-scale processes of hydrogen exchange by lowering activation energy. The general field of catalysis is relatively wide and well-developed, with a large number of various catalytic materials where metallic $\mathrm{Ni}$, especially at nanolevel, plays a significant role. NiNPs are among the most important catalysts, being tested for refining petroleum, conversion of automobile exhaust, hydrogenation of carbon monoxide and fats, etc. Ni-based catalysts usually consist of an active phase, for example, NiNPs dispersed on a support. Historically, it is assumed that NiNPs might be active centers for hydrogen dissociation, while the role of their support is not fully understood. A subtle change during catalyst preparation (size, shape, density, and distribution of NiNPs; introduction of NiNPs in a support and chemical interaction between them; value of surface area for porous $\mathrm{Ni}$; etc.) may result in dramatic alteration of its properties. Another problem is that nanostructured $\mathrm{Ni}$ catalysts become rapidly deactivated when exposed to air oxidized at surface. Therefore, activation process in hydrogen atmosphere is required in order to regain their catalytic properties, and their further handling under inert atmosphere is strongly recommended (e.g., pure argon).

In 2014 two experimental works were dedicated to decomposition-formation of $\mathrm{Mg}\left(\mathrm{BH}_{4}\right)_{2}$ with NiNPs as catalysts. ${ }^{53,54}$ Nanocomposite as milled mixture of $\mathrm{Mg}\left(\mathrm{BH}_{4}\right)_{2}$ with NiNPs was tested to study NiNP effect on the reversible hydrogenation of the borohydride. ${ }^{53}$ It was experimentally found that chemical reactions between NiNPs and $\mathrm{Mg}\left(\mathrm{BH}_{4}\right)_{2}$ did not take place during ball milling, although crystallinity of the borohydride decreased. During hydrogenation NiNPs reacted with $\mathrm{Mg}\left(\mathrm{BH}_{4}\right)_{2}$ to form thermodynamically stable $\mathrm{Ni}_{3} \mathrm{~B}$. Hydrogen desorption resulted in the formation of a reversible phase, which was identified by ${ }^{11} \mathrm{~B}$ NMR as $\operatorname{Mg}\left(\mathrm{B}_{3} \mathrm{H}_{8}\right)_{2}$. Incorporation of NiNPs into $\mathrm{Mg}\left(\mathrm{BH}_{4}\right)_{2}$ enhanced the kinetics of hydrogen desorption from $\mathrm{Mg}\left(\mathrm{BH}_{4}\right)_{2}$ and resulted in hydrogen desorption at lower temperatures.

Formation of $\mathrm{Mg}\left(\mathrm{BH}_{4}\right)_{2}$ was experimentally found by reaction (6) in the presence of NiNPs: ${ }^{54}$

$$
\mathrm{MgH}_{2 \text { solid }}+\mathrm{B}_{2} \mathrm{H}_{6 \text { gas }} \rightarrow \mathrm{Mg}\left(\mathrm{BH}_{4}\right)_{2} \text { solid }
$$

Solid $\mathrm{MgH}_{2}$ was nanoconfined in carbon nanoscaffold previously decorated with NiNPs and treated under $\mathrm{B}_{2} \mathrm{H}_{6} / \mathrm{H}_{2}$ gaseous mixture. This solvent-free method was found to be a new nanotechnological approach resulting in magnesium boron hydrides that were selectively formed inside nanopores (Fig. 10).

Addition of NiNPs opened a new possibility to control the reaction rate and even reaction mechanism. The reaction with $\mathrm{B}_{2} \mathrm{H}_{6}$ could occur at $303 \mathrm{~K}$, and various magnesium boron hydrides could be formed, while domination of both $\mathrm{MgB}_{12} \mathrm{H}_{12}$ and $\mathrm{Mg}\left(\mathrm{BH}_{4}\right)_{2}$ would be observed at $393 \mathrm{~K}$. Unambiguous role of NiNPs in this case is not clear. Although it was well-known that addition of NiNPs might lead to a substantial increase in reversibility for hydrogen desorption-absorption of complex metal hydrides ${ }^{55}$ and formation of a variety of $\mathrm{Ni}_{\mathrm{x}} \mathrm{B}$ compounds that might act as a site to 'store $\mathrm{B}$ reversibly' facilitating the reaction. ${ }^{56}$ The presence of $\mathrm{Mg}_{2} \mathrm{NiH}_{4}$ intermetallic hydride could also facilitate $\mathrm{Mg}\left(\mathrm{BH}_{4}\right)_{2}$ formation.

Metallic Ni surfaces are well-known to be excellent catalysts for hydrogenation reactions, therefore, Ni-based materials, for example Ti-Ni alloys, were effective metalhydride (MH) electrodes. ${ }^{57}$ Surface analysis of Ti-Ni alloys ${ }^{58}$ revealed a lot of processing-related impurities in the form of Ti carbides and oxides. It was concluded that $\mathrm{TiO}_{2}$ or $\mathrm{TiC}$ film should participate in charge-transfer reactions and could affect hydrogen diffusion into the bulk of MH electrode.
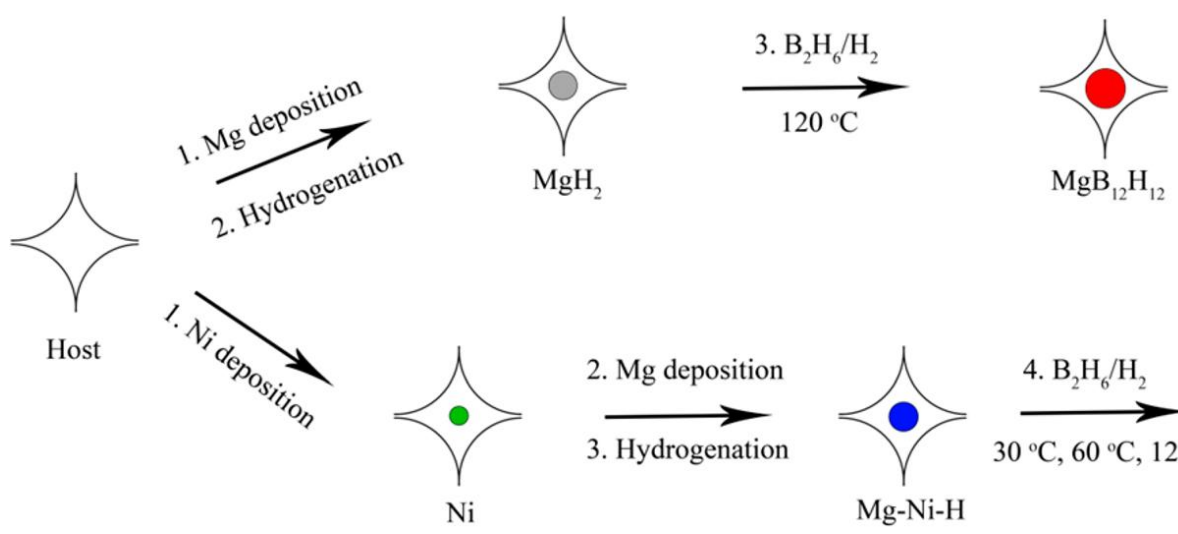

Fig. 10. Schematic overview of the strategy of synthesis of magnesium boron hydride compounds inside porous carbon nanoscaffold. Nanoconfined $\mathrm{MgH}_{2}$ was treated under $\mathrm{B}_{2} \mathrm{H}_{6} / \mathrm{H}_{2}$ pressure to form mainly $\mathrm{MgB}_{12} \mathrm{H}_{12}$ (upper route) or mixtures of magnesium boron hydrides including $\mathrm{Mg}\left(\mathrm{BH}_{4}\right)_{2}$ when the nanoscaffold was previously decorated with NiNPs (lower route). Reprinted with permission. ${ }^{54}$ Copyright $@$ 2014, ACS Publications. All rights reserved. 


\section{Chemical Applications of Nanostructured Ni}

Today application of $\mathrm{Ni}$ is rapidly increasing since a different design of nanostructured $\mathrm{Ni}$ opens a huge variety of practical applications in different kinds of chemistry. MPNi started being used as current collectors and support for active materials of supercapacitors or batteries. Raney $\mathrm{Ni}$, that was developed in 1926 by American engineer Murray Raney for hydrogenation of vegetable oils, today is more often called 'spongy' $\mathrm{Ni}$ and still continues to develop as effective catalyst mainly in organic and electrochemistry. Porous Ni or NiNPs showed higher electrocatalytic activity during alcohol oxidation than bulk Au, Pd or Pt. Therefore, cost-effective nanostructured Ni might be recommended as effective anode for methanol, ethanol, or butanol fuel cell. Catalysis in organic chemistry should be paid special attention to, since organic molecules with their own functional groups have a special posture on pure Ni surface in a convenient way to react without delay. Historically, it was the very first chemical application of metallic Ni dispersed into microparticles. Since the beginning of the $21^{\text {st }}$ century, with the rising concern of multidrug resistance and scarcity of new antibiotics, the use of NiNPs in medicine has been undergoing renaissance. The size- and morphology-induced tunable properties of nanostructured $\mathrm{Ni}$ and their wide scope of applicability in pharmacy and biotechnology today draws global attention.

\subsection{Porous Ni as Current Collectors}

There are only a few research publications on the application of porous metal materials in supercapacitors, but porous $\mathrm{Ni}$ has come to be one of the first materials studied as current ones. Interdigital electrodes based on $\mathrm{Mn}_{3} \mathrm{O}_{4}$-porous $\mathrm{Ni}$ were fabricated using lithography method and demonstrated much higher volumetric specific capacitances than that of flat nickel film supported $\mathrm{Mn}_{3} \mathrm{O}_{4}$ in the same conditions. ${ }^{59}$ The value of volumetric specific capacitance of the $\mathrm{Mn}_{3} \mathrm{O}_{4}$-porous $\mathrm{Ni}$ electrode reached $533 \mathrm{~F} \cdot \mathrm{cm}^{-3}$ at the scan rate of $2 \mathrm{mV} \cdot \mathrm{s}^{-1}$. A flexible all-solid micro supercapacitor based on this electrode showed volumetric specific capacitance of $110 \mathrm{~F} \cdot \mathrm{cm}^{-3}$ at the current density of $20 \mu \mathrm{A} \cdot \mathrm{cm}^{-2}$, with capacitance retention rate of $\sim 95 \%$ after 5000 cycles. It was concluded that vertical pores in the porous $\mathrm{Ni}$ electrode did not just suit its fabrication but also played an important role in enhancing capacitive performance of supported $\mathrm{Mn}_{3} \mathrm{O}_{4}$ NPs.

A single-step route to honeycomb-like 3D porous $\mathrm{Ni} @ \mathrm{Cu}$ nanoscaffolds via hydrogen bubble dynamic template electrodeposition was proposed by $\mathrm{Xu}$ et al. $^{60}$
Obtained current collectors offered an outstanding cycling performance of $\mathrm{Li}$ plating/stripping $(>300$ cycles at $0.5 \mathrm{mAh} \cdot \mathrm{cm}^{-2}$ and $>200$ cycles at $1.0 \mathrm{mAh} \cdot \mathrm{cm}^{-2}$ ) or $\mathrm{Na}$ reversible deposition ( $>240,110$ and 50 cycles at $0.5,1.0$ and $2.0 \mathrm{mAh} \cdot \mathrm{cm}^{-2}$ ) attributed to their ability to effectively accommodate $\mathrm{Li} / \mathrm{Na}$ deposits in their porous networks and to delocalize charge distribution. Although the presence of nickel in the 3D Ni@Cu current collector replaced some volume, it would not reduce volumetric energy density of the electrode as compared to a dendritic porous $\mathrm{Li}$ deposition layer. Most probably, this was because of remarkably homogeneous $\mathrm{Li}$ deposition that fully filled the well-defined porous structure that acted as a nanoscaffold, leading to a highly stable cycling performance. This nanoconfinement effect in porous $\mathrm{Ni} @ \mathrm{Cu}$ nanoscaffolds opened a new way to develop $\mathrm{Li} / \mathrm{Na}$ metal battery technology.

\subsection{Raney Ni Electrode for Hydrogenation Reactions}

Hydrogen consumption and electrode potential were measured during hydrogenation of acetone in basic aqueous solution with $(\mathrm{Co}, \mathrm{Cr}, \mathrm{Cu}, \mathrm{Mo}, \mathrm{Ti})$-doped Raney $\mathrm{Ni}^{61}$ The reaction was carried out under pressure in an autoclave equipped with a reference electrode. Only for $\mathrm{Cr}$, Mo and Ti-modificated Raney Ni higher catalytic activity was found if compared to pristine Raney $\mathrm{Ni}$. Obtained experimental kinetic data obeyed the LangmuirHinshelwood mechanism that allowed calculation of the rate and adsorption equilibrium constants. Metallic catalyst NPs acted as a dispersed electrode, and an electrochemical double layer was formed at their surface. In the presence of hydrogen, the potential of metal was determined by the Nernst law for hydrogen electrode, and further addition of acetone resulted in the potential shifted to the positive region. The degree of initial potential shift $\left(\Delta E_{0}\right)$ measured when acetone was introduced in the reactor correlated very well with the physicochemical characteristics of the catalysts and their activities for acetone hydrogenation in the liquid phase. When $\mathrm{Cr}$, Mo and $\mathrm{Ti}$ NPs modified Raney Ni, they were oxidized, resulting in smaller value of $\Delta E_{0}$, while for metallic Co and $\mathrm{Cu}$ doped Raney $\mathrm{Ni}$, the $\Delta E_{0}$ value was higher than in pristine Raney $\mathrm{Ni}$. It was concluded that this is because $\mathrm{Cr}$, Mo and Ti oxides are Lewis acids and can adsorb the electron-rich carbonyl functional group. Hydrogen molecules dissociatively adsorbed to $\mathrm{H}$ atoms on $\mathrm{Ni}$ sites could migrate by a spillover effect to the oxide sites where reaction with adsorbed acetone molecules could take place. Low potential shift might be justified by the fact that metallic Ni surface was not involved in the catalysis for acetone, while it was responsible only for hydrogen dissociation. In contrast, on the undoped or $\mathrm{Co}$ and $\mathrm{Cu}$ 
doped Raney Ni acetone and hydrogen adsorption would take place on the metallic surface, giving way to a stronger potential shift. Hydrogenation of $n$-butyraldehyde to $n$-butanol was experimentally investigated with a unique cage-like structured carbon-composed Raney $\mathrm{Ni}$ catalyst. ${ }^{62}$ The catalyst was reinforced with in-situ grown carbon nanotubes. The powders of both phenol formaldehyde resin and $\mathrm{Ni}-\mathrm{Al}$ alloy $(48 \mathrm{wt} \% \mathrm{Ni})$ were mixed and then compressed and carbonized, followed by alkaline leaching. The prepared carbon-composed catalyst possesses high stiffness, good hydrogen adsorption capacity, perfect catalytic property, and high selectivity. Because of the used carbon composing method, carboncomposed Raney Ni catalyst might be recommended for other applications, such as carbon capture, energy storage, and redox reactions.

Chiral modification of Raney Ni using (2R,3R)tartaric acid was studied by Kukula et al. ${ }^{63}$ The prepared catalyst was used in enantioselective hydrogenation of methylacetoacetate (MAA) to methyl-(3R)-hydroxybutyrate. The influence of reaction conditions $(\mathrm{pH}$, temperature, time, concentration of modifier and comodifier) on the optical yield of MAA hydrogenation was systematically investigated. A considerable influence of the modifying conditions on the resulting enantioselectivity of the catalyst was evident. Optical yield was proportional to the modifying temperature and time, and its dependencies on the tartaric acid concentration and the modifying $\mathrm{pH}$ passed through a maximum. Significant adsorption of tartaric acid and subsequent complex formation of $\mathrm{Ni}$ and tartaric acid was experimentally found on the catalyst surface. In the next research work ${ }^{64}$ detailed surface analysis of this modified Raney Ni was made. Decreased content of $\mathrm{Al}$ in the modified catalysts, due to Al leaching to the modifying solution, and increased carbon content because of an adsorbed amount of tartaric acid was observed. XPS data confirmed $\mathrm{Ni}^{2+}$ and $\mathrm{Ni}^{0}$ in the ratio of approximately $1: 1$ on the catalyst surface while only $\mathrm{Ni}^{0}$ was found on the surface of Raney Ni.

Performance of Raney Ni electrodes with electrically conductive materials for hydrogen oxidation reaction (HOR) on an alkaline fuel cell was investigated in $6 \mathrm{M} \mathrm{KOH}$ solution at $353 \mathrm{~K}^{65}$ Because of enhanced electrode conductivity, increased electrolyte diffusivity, and enlargement of active sites performance of the Raney $\mathrm{Ni}$ electrode was improved. Carbon black and NiNPs added to the Raney Ni electrode promoted better performance of the Raney $\mathrm{Ni}$ electrode. Moreover, additives with higher value of electric conductivity and surface area showed higher performance of Raney Ni. Kiros and co-authors ${ }^{66}$ used Raney $\mathrm{Ni}$ as gas diffusion electrode for HOR and prepared it by a mixture of $\mathrm{Ni}$ and
Al with the weight ratio of 1:1. Additionally, modification with other alloy formations containing $2 \mathrm{wt} \%$ of $\mathrm{Cu}, \mathrm{Fe}$, $\mathrm{Cr}$, Ti and La was made for the Raney Ni electrode. Depending on the active layer composition, electrocatalytic activity of the electrode was decreased in the order of $\mathrm{Cr}>\mathrm{La}>\mathrm{Ti}>\mathrm{Cu}>\mathrm{Fe}$. The highest catalytic response was experimentally found for the $\mathrm{Cr}$ and $\mathrm{Ti}$ doped Raney Ni electrodes. This fact might be explained by the presence of $\mathrm{Cr}$ and $\mathrm{Ti}$ oxides. ${ }^{61}$ The surface analysis of the electrodes after electrochemical tests showed high concentrations of transition metals, with catalyst aggregation that caused structural and surface changes and affected both the activity of HOR and electrode stability at high current density. ${ }^{66}$ Combined experimental techniques and calculations of the surface conditions for activated MP Raney Ni produced via leaching of spray-atomized $\mathrm{Ni}$-Al precursor powders were described by Barnard et al.$^{67}$ Predicted surface areas from the kinetic Monte Carlo simulations were in good agreement with BET measurements of nitrogen physisorption for catalyst materials prepared from two different Ni-Al alloys. Surface concentrations of residual $\mathrm{Al}$ after leaching process predicted by Metropolis Monte Carlo simulations were in agreement with XPS results confirming absence of Al-Al bonding at the surface. It was concluded that activation energy responsible for diffusion of $\mathrm{Al}$ on the surface was lower than that for $\mathrm{Al}$ dissolution. The presence of residual unleached $\mathrm{Ni}_{2} \mathrm{Al}_{3}$ phase demonstrated influence on the amount of $\mathrm{Al}$ signal at the surface, measured with XPS. This effect was removed by using a precursor that did not contain residual $\mathrm{Ni}_{2} \mathrm{Al}_{3}{ }^{68}$

Raney Ni electrodes, prepared with atmospheric plasma spraying (APS), were actively studied in hydrogen evolution reaction (HER). ${ }^{69,70}$ Potentiodynamic Tafel analysis and electrochemical impedance spectroscopy (EIS) in $30 \% \mathrm{KOH}$ solutions within the temperature range of 303-353 K were used for the Raney Ni layers of 30, 100 and $300 \mu \mathrm{m}$ thickness. ${ }^{69}$ Cell efficiency values based on the higher heating value of hydrogen within the region of $96 \%$ was obtained for APS Raney Ni layers with the thickness of 100 and $300 \mu \mathrm{m}$ at current density of $300 \mathrm{~mA} \cdot \mathrm{cm}^{-2}$ and the temperature of $343 \mathrm{~K}$. This was accounted for by a very high electroactive area as well as enhanced kinetics obtained for these samples following the chemical and electrochemical activation procedures. Dependence of the temperature and hydrogen heat treatment on the electrochemical properties associated with HER were investigated by Kim et al. ${ }^{70}$ The APS Raney Ni electrode contained unleached NiAl phase that resulted in more active sites and hence showed higher current density than that of the polished Ni electrode. It was found that in alkaline electrolysis the value of 
operating temperature is proportional to the electrolyte ionic conductivity and electrode surface kinetics. During hydrogen heat treatment of Ni-Al-alloy coated electrode the NiAl phase disappeared. An increase in the durability of the APS Raney Ni electrode was anticipated due to the fact that $\mathrm{Al}$ in the coating layer spread to the Ni substrate after the hydrogen heat treatment, also resulting in faster deactivation and a 6-fold increase in the crystallite size $(\sim 6.7 \mathrm{~nm})$. Enhanced electrocatalytic HER was found for 1D graphitic nanofiber encapsulated $\mathrm{Ni} / \mathrm{NiO} \mathrm{NPs}$, prepared through electrospinning and subsequent carbonization-reduction calcination procedure. ${ }^{71}$ Obtained experimental results indicated that with precursor containing $\mathrm{Ni}^{2+}$ of $0.5 \mathrm{mmol}$ the product showed the highest HER performance in alkaline medium along with excellent electrode durability. When voltage was applied to the reaction system, the charge was transferred to the $\mathrm{Ni} / \mathrm{NiO} \mathrm{NPs}$ from the electrode through the graphite structure (Fig. 11). When it was transported to the active sites on the surfaces of $\mathrm{Ni} / \mathrm{NiO} \mathrm{NPs}$, reaction with water in the electrolyte formed $\mathrm{H}_{\mathrm{ads}}$ and then hydrogen molecules that eventually left catalyst surface.

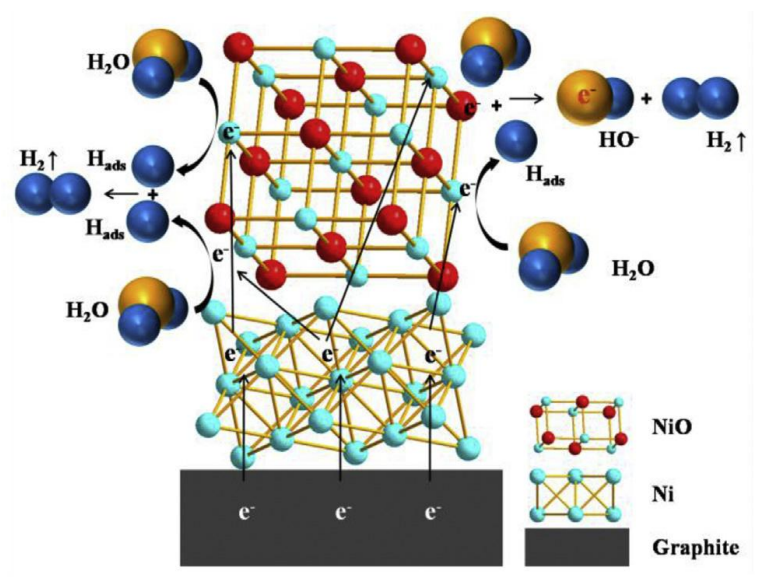

Fig. 11. Schematic mechanism of hydrogen evolution reaction for sample with precursor containing $0.5 \mathrm{mmol}$ of $\mathrm{Ni}^{2+}$. Reprinted with permission. ${ }^{71}$ Copyright (C) 2019, Elsevier B.V. All rights reserved

Uniform 1D porous structure provided a large specific surface area resulting in more active sites exposure on the electrode surface while homogeneous distribution and uniform size of $\mathrm{Ni} / \mathrm{NiO} \mathrm{NPs}$ promoted charge separation and transport to get high hydrogen evolution.

\subsection{Nanostructured Ni for Electrochemical Oxidation Reactions}

Recently, carbon material supported Ni or Ni-based alloys were confirmed as a promising catalyst of hydrogen oxidation reaction (HOR) in alkaline media for anion exchange membrane fuel cells (AEMFCs). ${ }^{72}$ Firstly, NiNPs supported on the N-doped carbon nanotubes with improved HOR performance were reported by Zhuang et $a l .73$ It was found that introduction of $\mathrm{N}$ atoms into carbon support altered the electronic structure of $\mathrm{Ni} d$-orbitals and reduced the hydrogen binding energy (HBE) on the $\mathrm{Ni}$ surface. This resulted in enhanced HOR activity that obeyed the Tafel-Volmer or Heyrovsky-Volmer processes: ${ }^{74}$

$$
\begin{gathered}
\mathrm{H}_{2} \leftrightarrow 2 \mathrm{H}_{\mathrm{ad}} \quad \text { (Tafel step) } \\
\mathrm{H}_{2}+\mathrm{OH}^{-} \leftrightarrow \mathrm{H}_{\mathrm{ad}}+\mathrm{H}_{2} \mathrm{O}+\overline{\mathrm{e}} \quad \text { (Heyrovsky step) } \\
\mathrm{H}_{\mathrm{ad}}+\mathrm{OH}^{-} \leftrightarrow \mathrm{H}_{2} \mathrm{O}+\overline{\mathrm{e}} \quad \text { (Volmer step) }
\end{gathered}
$$

According to the volcano-shaped curve, low or high HBE is adverse for HOR activity. ${ }^{75,76}$ Therefore, modification of carbon support, especially with $\mathrm{N}$ doping, would become an efficient way to regulate $\mathrm{HBE}$ on the $\mathrm{Ni}$ surfaces, hence optimizing HOR activity. It was concluded that adsorbed $\mathrm{H}_{\mathrm{ad}}$ on the catalyst surface played a key role in HOR activity, ${ }^{77}$ and especially on the $\mathrm{Ni}$ surface $\mathrm{H}_{\mathrm{ad}}$ adsorption was too strong to activate HOR. $^{78,79}$ Introduction of $\mathrm{N}$ into the carbon support was proven to reduce $\mathrm{H}_{\mathrm{ad}}$ adsorption on the Ni surface through metal-support electronic interaction. Besides, weak adsorption of $\mathrm{H}_{\mathrm{ad}}$ and oxidation of the $\mathrm{Ni}$ surface were confirmed experimentally. This resulted in the negative shift of Ni oxidation potential. ${ }^{80}$ The sample with an optimal surface $\mathrm{Ni}: \mathrm{N}$ atomic ratio of $\sim 0.34$ showed the best HOR kinetics that was accounted for by appropriate HBE on the Ni surface.

The next example of oxidation reaction with NiNPs might be electrochemical oxidation of butan-1-ol in alkali solution. ${ }^{81}$ NiNPs with the average diameter of $\sim 10 \mathrm{~nm}$ were tested through anode catalysis. Graphite-supported NiNPs formed $\mathrm{Ni}(\mathrm{OH})_{2}$ and then electrocatalytically active $\mathrm{NiOOH}$. It is well-known that oxidation of $\mathrm{Ni}$ to $\mathrm{Ni}(\mathrm{OH})_{2}$ in alkali solution gives a peak at around $0.5 \mathrm{~V}$ just after HER on Ni during anodic scan of potential. Therefore, the surface of NiNPs was primarily covered with $\mathrm{Ni}(\mathrm{OH})_{2}$ formed during exposition of a thin film electrode in the air and immersion in alkali solution for cyclic voltammetry (CV) measurement. The corresponding reverse peak was not found due to possible complexation of $\mathrm{Ni}^{2+}$ with oxidation products of ethylene glycol or of $\mathrm{NiOH}^{+}$destabilization. Conversion of $\mathrm{Ni}^{2+}$ to $\mathrm{Ni}^{3+}\left[\mathrm{Ni}(\mathrm{OH})_{2} / \mathrm{NiOOH}\right]$ and vice versa occurred according to reaction (10) with the peak at $\sim 0.51 \mathrm{~V}$ in anodic and at $\sim 0.35 \mathrm{~V}$ in cathodic directions:

$$
\mathrm{Ni}(\mathrm{OH})_{2}+\mathrm{OH}^{-} \leftrightarrow \mathrm{NiOOH}+\mathrm{H}_{2} \mathrm{O}+\overline{\mathrm{e}}
$$

Obtained $\mathrm{NiOOH}$ oxidized butanol and was reduced to $\mathrm{Ni}(\mathrm{OH})_{2}$ by the most possible chemical reactions:

$$
2 \mathrm{NiOOH}+\mathrm{C}_{4} \mathrm{H}_{10} \mathrm{O}=2 \mathrm{Ni}(\mathrm{OH})_{2}+\mathrm{C}_{4} \mathrm{H}_{8} \mathrm{O}
$$




$$
\begin{aligned}
& 2 \mathrm{NiOOH}+\mathrm{C}_{4} \mathrm{H}_{8} \mathrm{O}+\mathrm{OH}^{-}=2 \mathrm{Ni}(\mathrm{OH})_{2}+\mathrm{C}_{4} \mathrm{H}_{7} \mathrm{O}_{2}^{-}(12) \\
& 2 \mathrm{NiOOH}+\mathrm{C}_{4} \mathrm{H}_{7} \mathrm{O}_{2}^{-}+25 \mathrm{OH}= \\
& =2 \mathrm{Ni}(\mathrm{OH})_{2}+4 \mathrm{CO}_{3}{ }^{2-}+15 \mathrm{H}_{2} \mathrm{O}+18 \overline{\mathrm{e}}
\end{aligned}
$$

It was experimentally found that catalytic activity of the synthesized NiNPs depended on their size, purity, and molecular environment around the catalyst. The study revealed higher catalytic activity and increased ratio of carbonate to butanoate in the products using NiNPs obtained by reaction (2) with excess of hydrazine monohydrate and only $333 \mathrm{~K}$ heat treatment for $15 \mathrm{~min}$. These samples showed approximately a 2 and 14 times higher current density peak with respect to bulk Pd and $\mathrm{Pt}$ at the electrochemical oxidation of butan-1-ol.

Porous $\mathrm{Ni}$ is also actively used in oxidation reactions since it has a high value of conductivity and surface area, good permeability, and light weight. Threedimensional porous $\mathrm{Ni}$ was efficiently fabricated by controllable electrodeposition of Ni microparticles using hydrogen bubbles as the template at ambient temperature and pressure. ${ }^{82}$ Electrochemical measurements confirmed that obtained porous Ni possessed a good electrocatalytic activity for methanol and ethanol oxidation reaction due to both high surface area and open porous structures. Therefore, a good cycle life and catalytic properties of the prepared porous $\mathrm{Ni}$ encouraged promising prospects for its application not just as catalyst but also as sensor and purifier.

\subsection{Catalysis in Organic Chemistry with Nanostructured Ni}

Nickel atoms bound to organic ligands in complex compounds were actively used as universal catalysts in organic chemistry since different ligands could tune the electron density around the central Ni atom. Activated with methylaluminoxane $\alpha$-diimine nickel ${ }^{83}$ or o-diethyland o-diisopropyl nickel $^{84}$ demonstrated high catalytic activity towards olefin polymerization. Today NiNPs ${ }^{85,86}$ are more often used as catalyst in organic chemistry instead of well-known Ni complexes. Catalytic activity and stability of amorphous and crystalline NiNPs with the surface area of 250 and $110 \mathrm{~m}^{2} / \mathrm{g}$, respectively, was investigated at different time on stream (TOS) for ethanol decomposition. ${ }^{87}$ Heating of fresh amorphous NiNPs caused nucleation of crystalline NiNPs with fcc structure, crystal growth, and sintering below $473 \mathrm{~K}$ resulting in the decrease in the surface area $\left(65-146 \mathrm{~m}^{2} / \mathrm{g}\right)$ during hydrogen reduction (Fig. 12). The structure of amorphous NiNPs was continuously refined to form both fcc and hpc, as well as $\mathrm{Ni}_{3} \mathrm{C}$ and carbon layers that stabilized catalytic activity. The fcc structure of crystalline NiNPs remained unchanged during $96 \mathrm{~h}$ of TOS experiment indicating that carbon deposition might cause its initial deactivation.

At $523 \mathrm{~K}$, amorphous NiNPs showed $100 \%$ conversion, which remained constant during $96 \mathrm{~h}$ of TOS, while crystalline NiNPs initially exhibit $95 \%$ conversion and then slowly deactivate to $\sim 80 \%$ at $96 \mathrm{~h}$ TOS. This fact suggested that active sites on the used catalysts might be different as compared to the crystal structure of NiNPs. Activity $v s$. TOS results obtained at $473 \mathrm{~K}$ showed that amorphous NiNPs conversion increased from about 50 to $60-75 \%$, reaching a steady value at $\sim 30 \mathrm{~h}$ of TOS, which remained constant during the observed $96 \mathrm{~h}$ of TOS. Crystalline NiNPs initially exhibited higher conversion $(\sim 85 \%)$ but was quickly deactivated to the conversion within the similar range as amorphous NiNPs. Based on this study of the catalytic process for ethanol decomposition it was concluded that NiNPs might be proposed as affective catalyst for decomposition of other alcohols and even hydrocarbons to produce hydrogen.

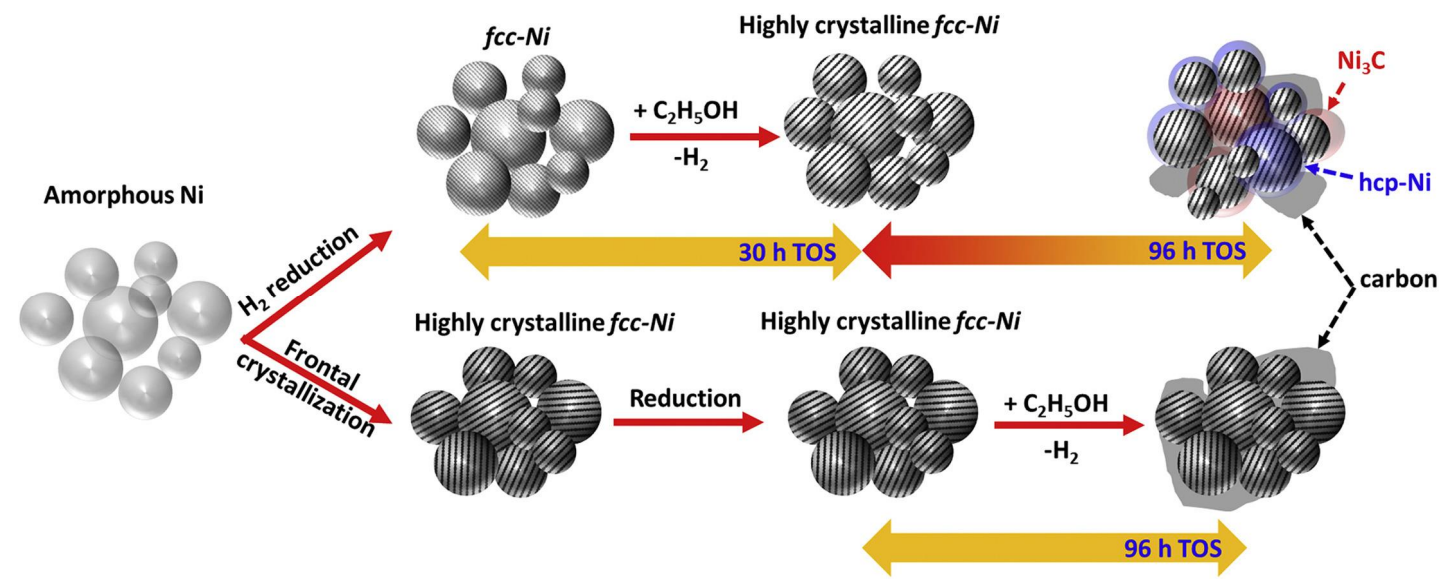

Fig. 12. Scheme of the behavior of amorphous and crystalline NiNPs for ethanol decomposition at different time on stream. Reprinted with permission. ${ }^{87}$

Copyright (C) 2018, Elsevier B.V. All rights reserved 
NiNPs containing polymethacrylic acid p(MAAc) hydrogel were applied as catalyst for degradation of a 4nitrophenol (4-NP). ${ }^{88}$ Carboxylic groups acted as highly efficient adsorption sites and their high degree was responsible for the removal of huge amounts of methylene blue (MB) and Rhodamine-6G (Rh-6G) from water. The maximum adsorption capacity of p(MAAc) hydrogel was 685 for $\mathrm{MB}$ and $1571 \mathrm{mg} \cdot \mathrm{g}^{-1}$ for $\mathrm{Rh}-6 \mathrm{G}$, and their adsorption data were best fit with the Langmuir- and Temkin adsorption isotherm, respectively. In a catalytic trial, a $0.05 \mathrm{~g}$ p(MAAc)-NiNPs composite and $0.19 \mathrm{~g}$ of $\mathrm{NaBH}_{4}$ were added to $50 \mathrm{ml}$ of $0.001 \mathrm{M}$ aqueous solution of 4-NP. Experimental value of the apparent rate constant for the reduction of 4-NP was as high as $0.038 \mathrm{~min}^{-1}$ and was proportional to both reaction temperature and catalyst dose. Furthermore, the catalyst was easily recoverable by a simple and fast process of filtration and only $20 \%$ loss in catalytic activity in the fourth consecutive cycle was observed. Prepared p(MAAc)-NiNPs composite might be recommended as a recoverable and reusable catalyst with a promising catalytic activity on the degradation of a nitro compound.

Experimental methods to fabricate $\mathrm{Ni}$ - and $\mathrm{Ni}$ CoNPs composites with polyvinylpyrrolidone (PVP) were developed by Ignatovich et al.$^{89}$ Catalytic activity of the composite towards reduction of substituted nitroarenes (nitropyrimidines containing pyridine and substituted aniline moieties) was examined. Catalytic activity of the PVP/NiNPs composite depended on the molecular weight of PVP connected to NiNPs. Conversion of 3-nitroaniline and the yield of 1,3-phenylenediamine were maximal in reactions catalyzed by the composites containing PVP with the molecular weight of 10 and $360 \mathrm{kDa}$, respectively. Catalytic properties of bimetallic Ni-Cu-, Ni$\mathrm{Ag}-$ and Ni-AuNPs with the average diameter within the range of $10-30 \mathrm{~nm}$ were studied by Knudsen effusion mass spectrometry (KEMS).$^{90}$ It was found that catalytic activity of NPs leading to the oxidation of the organic surface layer to $\mathrm{CO}_{2}$ at the final stage depended on the second element in the Ni-based nanoalloys. It was concluded that as regards to oleylamine oxidation catalytic activity decreases while thermodynamic stability of catalysts increases in the direction of $\mathrm{Ni}-\mathrm{Cu} \rightarrow \mathrm{Ni}-\mathrm{Ag} \rightarrow \mathrm{Ni}-\mathrm{Au}$.

Tada and co-aurthors ${ }^{91}$ reported $\mathrm{CO}_{2}$ methanation was carried out using porous $\mathrm{Ni}$ without any pretreatment. Because fabricated porous Ni with fcc structure possessed a great number of crystal defects, high-temperature treatment at the temperature of $573-873 \mathrm{~K}$ caused defect loss. It is well-known that active sites of porous $\mathrm{Ni}$ are low-coordination surface places resulting from defects, and density of active sites is directly related to catalyst activity. Porous $\mathrm{Ni}$ was stored in water at room temperature and dried in the air at room temperature for
$48 \mathrm{~h}$, that means surface oxidation was also possible. Under high space velocity $\left(4200 \mathrm{~h}^{-1}, 0.11 \mathrm{~mol}_{\mathrm{CO} 2} \cdot \mathrm{g}_{\text {cat }}{ }^{-1} \cdot \mathrm{h}^{-1}\right)$ porous $\mathrm{Ni}$ exhibited $\mathrm{CO}_{2}$ conversion of $83 \%$ at $523 \mathrm{~K}$ according to reaction (14) that might be considered as total reaction from both (15) and (16):

$$
\begin{gathered}
\mathrm{CO}_{2 \text { gas }}+4 \mathrm{H}_{2 \text { gas }} \rightarrow \mathrm{CH}_{4 \text { gas }}+2 \mathrm{H}_{2} \mathrm{O}_{\text {gas }} \\
\Delta_{r} \mathrm{H}^{0}=-165{\mathrm{~kJ} \cdot \mathrm{mol}^{-1}}^{-1} \\
\mathrm{CO}_{2 \text { gas }}+\mathrm{H}_{2 \text { gas }} \rightarrow \mathrm{CO}_{\text {gas }}+\mathrm{H}_{2} \mathrm{O}_{\text {gas }} \\
\Delta_{r} \mathrm{H}^{0}=+41 \mathrm{~kJ} \cdot \mathrm{mol}^{-1} \\
\mathrm{CO}_{\text {gas }}+3 \mathrm{H}_{2 \text { gas }} \rightarrow \mathrm{CH}_{4 \text { gas }}+\mathrm{H}_{2} \mathrm{O}_{\text {gas }} \\
\Delta_{r} \mathrm{H}^{0}=-206 \mathrm{~kJ} \cdot \mathrm{mol}^{-1}
\end{gathered}
$$

Obtained porous $\mathrm{Ni}$ might be considered as a promising new catalyst for $\mathrm{CO}_{2}$ methanation because it showed high activity that most probably derived from the great number of crystal defects in fcc crystal structure.

\subsection{Application of NiNPs in Biotechnologies}

In general, metal NPs are hydrophilic and highly stable as compared to organic materials. However, not every metal NP might be considered as nontoxic and biocompatible as NiNPs. Nevertheless, because of valuable properties (e.g., unique optical and magnetic properties, functionalization with various specific ligands to enhance their affinity towards target cells or molecules, etc.) NiNPs started to show new applications in biotechnology. ${ }^{92}$ Today modern drug delivery composites designed for enhanced drug efficacy and reduced adverse effects have evolved, accompanied by the development of novel materials. Recent advancement in biotechnology prepared excellent drug delivery matrices that work better than classical drug carriers (e.g., calcium phosphates). Nanostructured Ni might be considered as the material for drug delivery and tissue engineering.

It is well-known that people suffer from $\mathrm{Ni}$ allergy, ${ }^{93-95}$ and the first suspects were found in householding (e.g., jewelry or coins that contain Ni). Many agents have been developed to reduce penetration of Ni through skin, ${ }^{96,97}$ but only few of them are safe and effective. A thin layer of glycerine emollient containing NPs of $\mathrm{CaCO}_{3}$ or $\mathrm{Ca}_{3}\left(\mathrm{PO}_{4}\right)_{2}$ on an isolated piece of pig skin (in vitro) and on the skin of mice (in vivo) prevented penetration of $\mathrm{Ni}$ ions into the skin. ${ }^{98}$ Because of cation exchange NPs capture Ni ions and remain on the skin surface allowing them to be removed by simple washing with water. It was found that the usage of NPs with the average diameter $<500 \mathrm{~nm}$ in topical creams may be considered as an effective way to limit the exposure to metal ions that can cause skin irritation. Together with that the property of $\mathrm{Ni}$ allergy may be turned into useful application as a technique to destroy local malignancy on human skin using NiNPs or MPNi. ${ }^{99}$ It was tested whether surface modification of NiNPs could alter lung 
inflammation and injury in vivo induced by them. In order to compare the NiNPs ability to cause lung inflammation, injury, and fibrosis three samples were prepared - pure NiNPs, partially oxidized NiNPs and NiNPs coated with carbon. It was concluded that all three samples may cause lung injury and inflammation, however, their extent of pulmonary toxicity was different. Because of altered physicochemical properties surface modification of NiNPs with oxygen or carbon showed lower pulmonary effects for partially oxidized NiNPs and carbon coated NiNPs. The value of lung inflammation and injury with partially oxidized NiNPs was similar to those of pure NiNPs, but considerably decreased with carbon coated NiNPs. Only slight or no lung fibrosis was observed in case of carbon coated NiNPs and even partially oxidized NiNPs showed a significantly lower value than pure NiNPs.

A one-step process for the synthesis of hydrophilic carbon nanofibers (CNFs) through $\mathrm{CO}_{2}$ hydrogenation on NiNPs-Na/ $/ \mathrm{Al}_{2} \mathrm{O}_{3}$ was developed to prepare a NiNPs$\mathrm{Na} / \mathrm{Al}_{2} \mathrm{O}_{3} @ \mathrm{CNF}$ composite and applied for drug delivery. ${ }^{100}$ The main task was to load and deliver the anticancer drug doxorubicin (DOX). CNFs that exhibited a large content of hydrophilic oxygen-containing functional groups on the carbon surface resulted in an excellent colloidal solution and, hence, in a highly efficient DOX adsorption capacity. It was found that adsorption of DOX onto the NiNPs- $\mathrm{Na} / \mathrm{Al}_{2} \mathrm{O}_{3} @ \mathrm{CNF}$ composite relied on the strong electrostatic interaction between protonated DOX ( $\mathrm{R}^{-\mathrm{NH}^{3+}}$ ) and negative functional groups on CNFs, as well as on the typical $\pi-\pi$ stacking interaction. Therefore, the release of DOX was strongly $\mathrm{pH}$ dependent. An adequate magnetic response was accounted for by the presence of NiNPs in the NiNPs-Na/ $/ \mathrm{Al}_{2} \mathrm{O}_{3} @$ CNF composite. It was concluded that DOX-loaded NiNPs-Na/ $/ \mathrm{Al}_{2} \mathrm{O}_{3} @$ CNF drug carrier targeted cancer cells more selectively and effectively than free DOX and showed a marked tendency to kill HeLa cancer cells and reduce toxicity to normal human primary fibroblast (HPF) cells. Bimetallic Ni-FeNPs with the average diameter within the range of 20-200 nm were synthesized on the silica surface and applied for reductive degradation of the drug nimesulide in aqueous solution. ${ }^{101}$ Degradation of nimesulide was characterized by reduction of the nitro group and removal of the sulphonyl group, with the formation of an amine and thioester aromatic derivative product. It was concluded that $\mathrm{Ni}$ may act as catalyst to accelerate the redox reaction between $\mathrm{Fe}^{0}$ and nimesulide by capturing and converting molecular hydrogen into $\mathrm{H}^{*}$ radicals, which were eventually responsible for reductive degradation of numesulide. Thus, proposed silica-supported bimetallic Ni-FeNPs might be considered as a promising biomaterial for the elimination of nitro moiety present in nimesulide.

\section{Outlooks}

Synthetic approaches to nanostructured Ni fabrication are quite well-developed, however, their main parameters responsible for a certain geometry, morphology, and crystal structure of NiNPs or MPNi need to be systematized. This experimental data might be helpful for altering desirable properties of nanostructured Ni.

Properties of metallic $\mathrm{Ni}$ at nanolevel are still a new object since certain design of nanomaterial might disclose a new special feature. It was unexpected to see that MPNi possesses unique mechanical or magnetic properties when everyone has expected to get a higher catalytic activity because of the size effect and nothing more. Therefore, thorough studies with the focus on intrinsic properties of nanostructured $\mathrm{Ni}$ must be a very good and promising way to find a new application.

It is expected that nanocomposites made of NiNPs or MPNi will be actively investigated to multiply their properties with valuable $\mathrm{Ni}$ properties such as mechanical, optical, electronic, magnetic, catalytic, biological, etc. Control synthesis and good knowledge of nanostructured Ni properties might be a strong background for preparing a more complex nanomaterial with a valuable application in science and technology.

\section{Acknowledgements}

Financial support was provided by national project of the Ministry of Education and Science of Ukraine (0118U000268). I. Saldan expresses personal thanks to the Slovak Academic Information Agency (SAIA) as scholarship holder of National Scholarship Programme of the Slovak Republic in 2020.

\section{References}

[1] Scerri, E. The Periodic Table: Its Story and Its Significance; Oxford University Press: New York, 2007.

[2] Greenwood, N.; Earnshaw, A. Chemistry of the Elements, 2nd ed.; Butterworth-Heinemann: Oxford, 1997.

[3] Pfirrmann, S.; Limberg, C.; Herwig, C.; Stößer, R.; Ziemer, B. A Dinuclear Nickel(I) Dinitrogen Complex and its Reduction in Single-Electron Steps. Angew. Chem. Int. Ed. 2009, 48, 3357-3361. https://doi.org/10.1002/anie.200805862

[4] Roberts-Austen, W.C. The Extraction of Nickel from its Ores by the Mond Process. Nature 1898, 59, 63-64.

https://doi.org/10.1038/059063a0

[5] Housecroft, C.; Sharpe, A. Inorganic Chemistry, 4th ed; Pearson: London, 2012.

[6] Court, T.L.; Dove, M.F.A. Fluorine Compounds of Nickel(III). J. Chem. Soc., Dalton Trans. 1973, 19, 1995-1997.

https://doi.org/10.1039/DT9730001995

[7] Klaus, J. Dilithium-Nickel-Olefin Complexes. Novel Bimetal Complexes Containing a Transition Metal and a Main Group Metal. 
Angew. Chem. Int. Ed. 1975, 14, 752-753.

https://doi.org/10.1002/anie.197507521

[81 Solid State Electrochemistry II: Electrodes, Interfaces and Ceramic Membranes; Kharton, V.V., Ed.; Wiley-VCH: Weinheim, 2011.

[9] Raghavendra, A. High Frequency High Amplitude Magnetic Field Driving System for Magnetostrictive Actuators. PhD Dissertation, University of Maryland, 2009.

「10] Rao, B.G.; Mukherjee, D.; Reddy, B.M. Novel approaches for preparation of nanoparticles. In Nanostructures for novel therapy: Synthesis, Characterization and Applications. Micro and Nano Technologies; Ficai, D.; Grumezescu, A.M., Eds.; Elsevier; Amsterdam, 2017; pp 1-36.

[11] Donegan, K.P.; Godsell, J.F.; Otway, D.J.; Morris, M.A.; Roy, S.; Holmes, J.D. Size-Tuneable Synthesis of Nickel Nanoparticles. J. Nanopart. Res., 2012, 14, 670. https://doi.org/10.1007/s11051011-0670-y

[12] Zhu, W.-H.; Zhang, D.-J.; Xhang, G.-Dg.; Ke, J.-J. Sintering Preparation for Porous Plaque Containing Hollow Nickel Fiber.

Mater. Res. Bull. 1995, 30, 1133-1140.

https://doi.org/10.1016/0025-5408(95)00101-8

[13] Jamkhande, P.G.; Ghule, N.W.; Bamer, A.H.; Kalaskar, M.G. Metal Nanoparticles Synthesis: An Overview on Methods of Preparation, Advantages and Disadvantages, and Applications. $J$. Drug Deliv. Sci. Tec. 2019, 53, 101174.

https://doi.org/10.1016/j.jddst.2019.101174

[14] Liu, X.; Guo, M.; Zhang, M.; Wang, X. Effects of PVP on the Preparation and Growth Mechanism of Monodispersed Ni Nanoparticles. Rare Metals 2008, 27, 642-647.

https://doi.org/10.1016/S1001-0521(08)60198-9

[15] Wu, Z.G.; Munoz, M.; Montero, O. The Synthesis of Nickel Nanoparticles by Hydrazine Reduction. Adv. Powder Technol. 2010, 21, 165-168. https://doi.org/10.1016/j.apt.2009.10.012

[16] Nakano, K. Synthesis of Nickel Nanoparticles from Nickel Hydrazine Complex Solution Using Ultrasonication. Chem. Lett. 2016, 45, 131-133. https://doi.org/10.1246/cl.150967

[17] Simakova, I.L.; Simonov, M.N.; Demidova, Y.S.; Murzin, D.Y. Size-Controlled Reverse Microemulsion Synthesis of Ni and Co Metal Nanoparticles. Mater. Today 2017, 4, 11385-11391. https://doi.org/10.1016/j.matpr.2017.09.014

[18] Wang, H.; Wu, L.; Wang, Y.; Li, X.; Wang, Y. Facile Synthesis of Ni Nanoparticles from Triangular $\mathrm{Ni}\left(\mathrm{HCO}_{3}\right)_{2}$ Nanosheets as Catalysts for Hydrogen Generation from Hydrous Hydrazine. Catal. Commun. 2017, 100, 33-37. https://doi.org/10.1016/j.catcom.2017.06.021

[19] Cheng, J.; Zhang, X.; Ye, Y. Synthesis of Nickel Nanoparticles and Carbon Encapsulated Nickel Nanoparticles Supported on Carbon Nanotubes. J. Solid State Chem. 2006, 179, 91-95. https://doi.org/10.1016/j.jssc.2005.10.001

[20] Zhang, Y.-X.; Fu, W.-J.; An, X.-Q. Preparation of Nickel Nanoparticles in Emulsion. Trans. Nonferrous Met. Soc. China 2008, 18, 212-216. https://doi.org/10.1016/S1003-6326(08)60038-2 [21] Li, P.; Deng, G.; Guo, X.; Liu, H.; Jiang, W.; Li, F. Preparation of Nickel and $\mathrm{Ni}_{3} \mathrm{Sn}$ Nanoparticles via Extension of Conventional Citric Acid and Ethylene Diamine Tetraacetic Acid Mediated SolGel Method. J. Alloys Compd. 2016, 668, 159-168.

https://doi.org/10.1016/j.jallcom.2016.01.203

[22] Li, M.; Chen, Y.; Ji, N.; Zeng, D.; Peng, D.-L. Preparation of Monodisperse Ni Nanoparticles and their Assembly into 3D Nanoparticle Superlattices. Mater. Chem. Phys. 2014, 147, 604-610. https://doi.org/10.1016/j.matchemphys.2014.05.036
[23] Morozov, Yu.G.; Belousova, O.V.; Kuznetsov, M.V. Preparation of Nickel Nanoparticles for Catalytic Applications. Inorg. Mater. 2011, 47, 36-40.

https://doi.org/10.1134/S0020168510121027

[24] Jung, J.-S.; Chae, W.-S.; McIntyre, R.A.; Seip, C.T.; Wiley, J.B.; O'Connor, C.J. Preparation and Characterization of Ni Nanoparticles in an MCM Mesoporous Material. Mater. Res. Bull. 1999, 34, 1353-1360.

https://doi.org/10.1016/S0025-5408(99)00146-4

[25] Okada, Y.; Matsumoto, S.; Kinoshita, T. Preparation of Nickel Nanoparticle-Deposited Silica Microsphere Catalysts. J. Chem. Eng. Jpn. 2019, 52, 605-609. https://doi.org/10.1252/jcej.18we313

[26] Zhang, Y.; Yang, Y.; Xiao, P.; Zhang, X.; Lu, L.; Li, L.

Preparation of Ni Nanoparticle- $\mathrm{TiO}_{2}$ Nanotube Composite by Pulse Electrodeposition. Mater. Lett. 2009, 63, 2429-2431.

https://doi.org/10.1016/j.matlet.2009.08.019

[27] Wang, C.-C.; Chou, P.-H.; Yu, Y.-H.; Kei, C.-C. Deposition of $\mathrm{Ni}$ Nanoparticles on Black $\mathrm{TiO}_{2}$ Nanowire Arrays for

Photoelectrochemical Water Splitting by Atomic Layer Deposition. Electrochim. Acta 2018, 284, 211-219.

https://doi.org/10.1016/j.electacta.2018.07.164

[28] Atashbar, M.Z.; Bliznyuk, V.; Banerji, D.; Singamaneni, S. Deposition and Manipulation of Nickel Nanoparticles. Proceedings of International Conference on Intelligent Sensing and Information Processing (ICISIP-2004), 4-7 Jan. 2004, Chennai, India, pp 258261. doi: 10.1109/ICISIP.2004.1287663

[29] Chen, R.; Maclaughlin, S.; Botton, G.; Zhu, S. Preparation of Ni-g-Polymer Core-Shell Nanoparticles by Surface-Initiated Atom Transfer Radical Polymerization. Polymer 2009, 50, 4293-4298. https://doi.org/10.1016/j.polymer.2009.07.012

[30] Li, J.; Guo, Q.; Shi, J.; Gao, X.; Feng, Z.; Fan, Z.; Liu, L. Preparation of Ni Nanoparticle-Doped Carbon Fibers. Carbon 2012, 50, 2045-2047. https://doi.org/10.1016/j.carbon.2011.12.004 [31] Jung, K.Y.; Lee, J.H.; Koo, H.Y.; Kang, Y.C.; Park, S.B. Preparation of Solid Nickel Nanoparticles by Large-Scale Spray Pyrolysis of $\mathrm{Ni}\left(\mathrm{NO}_{3}\right)_{2} \cdot 6 \mathrm{H}_{2} \mathrm{O}$ Precursor: Effect of Temperature and Nickel Acetate on the Particle Morphology. Mater. Sci. Eng. B. 2007, 137, 10-19. https://doi.org/10.1016/j.mseb.2006.09.025 [32] Tan, M.I.S.M.H.; Omar, A.F.; Rashid, M.; Hashim, U. VISNIR Spectral and Particles Distribution of $\mathrm{Au}, \mathrm{Ag}, \mathrm{Cu}, \mathrm{Al}$ and $\mathrm{Ni}$ Nanoparticles Synthesized in Distilled Water Using Laser Ablation. Results Phys. 2019, 14, 102497.

https://doi.org/10.1016/j.rinp.2019.102497

[33] Zaitsev, A.Y.; Wilkinson, D.S.; Weatherly, G.C.; Stephenson, T.F. The Preparation of Highly Porous Structures from Filamentary Nickel Powders. J. Power Sources 2003, 123, 253-260.

https://doi.org/10.1016/S0378-7753(03)00534-2

[34] Srivastava, D.N.; Pol, V.G.; Palchik, O.; Zhang, L.; Yu, J.C.; Gedanken, A. Preparation of Stable Porous Nickel and Cobalt Oxides Using Simple Inorganic Precursor, Instead of Alkoxides, by a Sonochemical Technique. Ultrason. Sonochem. 2005, 12, 205212. https://doi.org/10.1016/j.ultsonch.2004.01.003

[35] Zhu, P.; Zhao, Y. Cyclic Voltammetry Measurements of Electroactive Surface Area of Porous Nickel: Peak Current and Peak Charge Methods and Diffusion Layer Effect. Mater. Chem. Phys. 2019, 233, 60-67.

https://doi.org/10.1016/j.matchemphys.2019.05.034

[36] Tao, L.; Ying, L.; Guohua, M. Preparation of Submicro-porous Nickel Wafers by Molding-Decomposition-Sintering Method Using Nickel Oxalate Nano-Rods as Precursors. Rare Metal Mat. Eng. 2016, 45, 1396-1400. https://doi.org/10.1016/S1875-

5372(16)30120-5 
[37] Mohamed, L.Z.; Ghanem, W.A.; El-Kady, O.A.; Lotfy, M.M.; Ahmed, H.A.; Elrefaie, F.A. Oxidation Characteristics of PorousNickel Prepared by Powder Metallurgy and Cast-Nickel at $1273 \mathrm{~K}$ in Air for Total Oxidation Time of 100 h. J. Adv. Res. 2017, 8, 717729. https://doi.org/10.1016/j.jare.2017.08.004

[38] Wu, L.-S.; Wen, X.-P.; Wen, H.; Dai, H.-B.; Wang, P. Palladium Decorated Porous Nickel Having Enhanced Electrocatalytic Performance for Hydrazine Oxidation. J. Power Sources 2019, 412, 71-77.

https://doi.org/10.1016/j.jpowsour.2018.11.023

[39] El Naggar, A.M.A.; Kazak, C. Preparation and Characterization of Novel Nano-Structured Porous Nickel Alloy Composite Induced by Electroless Deposition and its Performance in the Hydrogen Separation. Sep. Purif. Technol. 2016, 160, 73-80. https://doi.org/10.1016/j.seppur.2016.01.015

[40] Sharma, A.; Hickman, J.; Gazit, N.; Rabkin, E.; Mishin, Y. Nickel Nanoparticles Set a New Record of Strength. Nat. Commun. 2018, 9, 4102. https://doi.org/10.1038/s41467-018-06575-6 [41] Chen, L.; Xu, H.; Cui, H.; Zhou, H.; Wan, H.; Chen, J. Preparation of $\mathrm{Cu}-\mathrm{Ni}$ Bimetallic Nanoparticles Surface-Capped with Dodecanethiol and their Tribological Properties as Lubricant Additive. Particuology 2017, 34, 89-96.

https://doi.org/10.1016/j.partic.2016.12.006

[42] Lu, A.-H.; Salabas, E.L.; Schuth, F. Magnetic Nanoparticles: Synthesis, Protection, Functionalization, and Application. Angew. Chem. Int. Ed. 2007, 46, 1222-1244. https://doi.org/10. 1002/anie. 200602866

[43] Luo, X.; Chen, Y.; Yue, G.-H.; Peng, D.-L.; Luo, X. Preparation of Hexagonal Close-Packed Nickel Nanoparticles via a Thermal Decomposition Approach Using Nickel Acetate Tetrahydrate as a Precursor. J. Alloy. Compd. 2009, 476, 864-868. https://doi.org/10.1016/j.jallcom.2008.09.117

[44] Zhao, S.W.; Wang, K.Y.; Wu, J.C.; Zhan, C.Y.; Zou, Y. The Mechanism of Negative and Positive Hydrogen Ions Production on the Ni Surface. Vacuum 2020, 171, 108982.

https://doi.org/10.1016/j.vacuum.2019.108982

[45] Zhang, L.; Jin, L.; Zhang, B.; Deng, W.; Pan, H.; Tang, J.; Zhu, M.; Yang, W. Multifunctional Triboelectric Nanogenerator Based on Porous Micro-Nickel Foam to Harvest Mechanical Energy. Nano Energy 2015, 16, 516-523.

https://doi.org/10.1016/j.nanoen.2015.06.012

[46] Zhang P., Zuo F., Urban F.K.; Khabari, A.; Griffiths, P.; Hosseini-Tehrani, A. Irreversible Magnetization in Nickel Nanoparticles. J. Magn. Magn. Mater. 2001, 225, 337-345. https://doi.org/10.1016/S0304-8853(00)01379-2

[47] Liu, S.; Mei, J.; Zhang, C.; Zhang, J.; Shi, R. Synthesis and Magnetic Properties of Shuriken-Like Nickel Nanoparticles. $J$. Mater. Sci. Technol. 2018, 34, 836-841.

https://doi.org/10.1016/j.jmst.2017.04.006

[48] Singh, J.; Patel, T.; Kaurav, N.; Okram, G.S. Synthesis and Magnetic Properties of Nickel Nanoparticles. Proceed. AIP Conference, 1731, 2016, 050036. https://doi.org/10.1063/1.4947690 [49] Manukyan, A.S.; Avakyan, L.A.; Elsukova, A.E.; Zubavichus, Y.V.; Sulyanov, S.N.; Mirzakhanyan, A.A., Kolpacheva, N.A.; Spasova, M.; Kocharian, A.N.; Farle, M. et al. Formation of Nickel Nanoparticles and Magnetic Matrix in Nickel Phthalocyanine by Doping with Potassium. Mater. Chem. Phys. 2018, 214, 564-571. https://doi.org/10.1016/j.matchemphys.2018.04.068

[50] El Komy, G.M.; Abomostafa, H.; Azab, A.A.; Selim, M.M. Innovative Synthesis of Nickel Nanoparticles in Polystyrene Matrix with Enhanced Optical and Magnetic Properties. J. Inorg.

Organomet. Polym. Mater. 2019, 29, 1983-1994.

https://doi.org/10.1007/s10904-019-01157-5
[51] Aneli, J.; Nadareishvili, L.; Mamniashvili, G.; Akhalkatsi, A.; Zaikov, G. Gradiently Anisotropic Conducting and Magnetic Polymer Composites. Chem. Chem. Technol. 2012, 6, 285-289. https://doi.org/10.23939/chcht06.03.285

[52] Liu, Y.B.; Jin, R.; Qiu, J.; Liu, L.H. Spectral Radiative Properties of a Nickel Porous Microstructure and Magnetic Polariton Resonance for Light Trapping. Int. J. Heat Mass Transfer 2016, 98, 833-844.

https://doi.org/10.1016/j.ijheatmasstransfer.2016.03.071 [53] Saldan, I.; Hino, S.; Humphries, T.D.; Zavorotynska, O.; Chong, M.; Jensen, C.M.; Deledda, S.; Hauback, B.C. Structural Changes Observed during the Reversible Hydrogenation of $\mathrm{Mg}\left(\mathrm{BH}_{4}\right)_{2}$ with Ni-Based Additives. J. Phys. Chem. C 2014, 118 , 23376-23384. https://doi.org/10.1021/jp5066677

[54] Au, Y.S.; Yan, Y.; de Jong, K.P.; Remhof, A.; de Jongh, P.E. Pore Confined Synthesis of Magnesium Boron Hydride Nanoparticles. J. Phys. Chem. C 2014, 118, 20832-20839. https://doi.org/10.1021/jp507568p

[55] Ngene, P.; van Zwienen, R.; de Jongh P.E. Reversibility of the Hydrogen Desorption from $\mathrm{LiBH}_{4}$ : A Synergetic Effect of Nanoconfinement and Ni Addition. Chem. Commun. 2010, 46, 8201-8203. https://doi.org/10.1039/C0CC03218B

[56] Ngene, P.; Verkuijlen M.H.W.; Zheng, Q.; Kragten, J.; van Bentum, P.J.M.; Bitter, J.H.; de Jongh., P.E. The Role of Ni in Increasing the Reversibility of the Hydrogen Release from Nanoconfined $\mathrm{LiBH}_{4}$. Faraday Discuss. 2011, 151, 47-58. https://doi.org/10.1039/c0fd00028k

[57] Saldan, I.; Burtovyy, R.; Becker, H.-W.; Ader, V.; Wöll, Ch. Ti-Ni Alloys as MH Electrodes in Ni-MH Accumulators. Int. J. Hydrog. Energy 2008, 33, 7177-7184.

https://doi.org/10.1016/j.ijhydene.2008.09.002

[58] Saldan, I.; Frenzel, J.; Shekhah, O.; Chelmowski, R.; Birkner, A.; Wöll, Ch. Surface of Ti-Ni Alloys after their Preparation. $J$. Alloys Compd. 2009, 470, 568-673.

https://doi.org/10.1016/j.jallcom.2008.03.050

[59] Li, X.-J.; Song, Z.-W.; Zhao, Y.; Wang, Y.; Zhao, X.-C.; Liang, M.; Chu, W.-G.; Jiang, P.; Liu, Y. Vertically Porous Nickel Thin Film Supported $\mathrm{Mn}_{3} \mathrm{O}_{4}$ for Enhanced Energy Storage Performance. J. Colloid Interface Sci. 2016, 483, 17-25. https://doi.org/10.1016/j.jcis.2016.08.006

[60] Xu, Y.; Menon, A.S.; Harks, P.-P.R.M.L.; Hermes, D.C.; Haverkate, L.A., Unnikrishnan, S.; Mulder, F.M. Honeycomb-Like Porous 3D Nickel Electrodeposition for Stable Li and Na Metal Anodes. Energy Storage Mater. 2018, 12, 69-78.

https://doi.org/10.1016/j.ensm.2017.11.011

[61] Pardillos-Guindet, J.; Metais, S.; Vidal, S.; Court, J.; Fouilloux, P. Electrode Potential of a Dispersed Raney Nickel Electrode During Acetone Hydrogenation: Influence of the Promoters. Appl. Catal. A: Gen. 1995, 132, 61-75.

https://doi.org/10.1016/0926-860X(95)00152-2

[62] Jiang, H.; Lu, S.; Zhang, X.; Peng, H.; Qiao, J. Preparation and Application of a Novel Raney Nickel Catalyst for Fix-Bed Reactions. Catal. Commun. 2019, 118, 60-64. https://doi.org/10.1016/j.catcom.2018.10.002

[63] Kukula, P.; Červený, L. Preparation of Tartaric Acid Modified Raney Nickel Catalysts: Study of Modification Procedure. Appl. Catal. A: Gen. 2001, 210, 237-246. https://doi.org/10.1016/S0926860X(00)00812-7

[64] Kukula, P.; Červený, L. Characterization of Chirally Modified Raney Nickel and Compounds of Tartaric Acid and Nickel. Appl. Catal. A: Gen. 2002, 223, 43-55. https://doi.org/10.1016/S0926$860 \times(01) 00741-4$ 
[65] Shim, J.; Lee, H.-K. Improved Performance of Raney Nickel Electrode by the Addition of Electrically Conductive Materials for Hydrogen Oxidation Reaction. Mater. Chem. Phys. 2001, 69, 72-76. https://doi.org/10.1016/S0254-0584(00)00349-7

[66] Kiros, Y.; Majari, M., Nissinen, T.A. Effect and

Characterization of Dopants to Raney Nickel for Hydrogen

Oxidation. J. Alloys Compd. 2003, 360, 279-285.

https://doi.org/10.1016/S0925-8388(03)00346-3

[67] Barnard, N.C.; Brown, S.G.R.; Devred, F.; Bakker, J.W.; Nieuwenhuys, B.E.; Adkins, N.J. A Quantitative Investigation of the Structure of Raney-Ni catalyst Material Using Both Computer Simulation and Experimental Measurements. J. Catal. 2011, 281, 300-308. https://doi.org/10.1016/j.jcat.2011.05.010

[68] Devred, F.; Reinhart, G.; Iles, G.N.; Van Der Klugt, B.; Adkins, N.J.E.; Bakker, J.W., Nieuwenhuys, B.E. Synchrotron XRay Microtomography of Raney-Type Nickel Catalysts Prepared by Gas Atom Isation: Effect of Microstructure on Catalytic

Performance. Catal. Today 2011, 163, 13-19.

https://doi.org/10.1016/j.cattod.2010.01.054

[69] Chade, D.; Berlouis, L.; Infield, D.; Cruden, A.; Nielsen, P.T.; Mathiesen, T. Evaluation of Raney Nickel Electrodes Prepared by Atmospheric Plasma Spraying for Alkaline Water Electrolysers. Int. J. Hydrog. Energy 2013, 38, 14380-14390.

https://doi.org/10.1016/j.ijhydene.2013.09.012

[70] Kim, J.-E.; Bae, K.-K.; Park, C.-S.; Jeong, S.-U.; Baik, K.-H.; Kim, J.-W.; Kang, K.-S.; Lee, K.-B.; Kim, Y.-H. Electrochemical Characterization of Raney Nickel Electrodes Prepared by Atmospheric Plasma Spraying for Alkaline Water Electrolysis. $J$. Ind. Eng. Chem. 2019, 70, 160-168.

https://doi.org/10.1016/j.jiec.2018.10.010

[71] Wang, P.; Zhang, X.; Wie, Y.; Yang, P. Ni/NiO Nanoparticles Embedded Inporous Graphite Nanofibers Towards Enhanced Electrocatalytic Performance. Int. J. Hydrog. Energy 2019, 44, 19792-19804. https://doi.org/10.1016/j.ijhydene.2019.05.121

[72] Jiang, S.; Cheng, Q.; Zou, L.; Zou, Z.; Li, Y.; Zhang, Q.; Gao, Y.; Yang, H. Ni Nanoparticles Supported on Carbon Nanosheets with Tunable N Doping Content for Hydrogen Oxidation Reaction. Chem. Phys. Lett. 2019, 728, 19-24.

https://doi.org/10.1016/j.cplett.2019.04.072

[73] Zhuang, Z.; Giles, S.A.; Zheng, J.; Jenness, G.R.; Caratzoulas, S.; Vlachos, D.G.; Yan, Y. Nickel Supported on Nitrogen-Doped Carbon Nanotubes as Hydrogen Oxidation Reaction Catalyst in Alkaline Electrolyte. Nat. Commun. 2016, 7, 10141.

https://doi.org/10.1038/ncomms10141

[74] Gao, L.; Wang, Y.; Li, H.; Li, Q.; Ta, N.; Zhuang, L.; Fu, Q.; Bao, X. A Nickel Nanocatalyst within a h-BN Shell for Enhanced Hydrogen Oxidation Reactions. Chem. Sci. 2017, 8, 5728-5734. https://doi.org/10.1039/C7SC01615H

[75] Skúlason, E.; Tripkovic, V.; Björketun, M.E.; Gudmundsdóttir, S.; Karlberg, G.; Rossmeisl, J.; Bligaard, T.; Jónsson, H.; Nørskov, J.K. Modeling the Electrochemical Hydrogen Oxidation and Evolution Reactions on the Basis of Density Functional Theory Calculations. J. Phys. Chem. C 2010, 114, 18182-18197. https://doi.org/10.1021/jp1048887

[76] Nørskov, J.K.; Bligaard, T.; Logadottir, A.; Kitchin, J.R.; Chen, J.G.; Pandelov, S.; Stimming, U. Trends in the Exchange Current for Hydrogen Evolution. J. Electrochem. Soc. 2005, 152, J23. https://doi.org/10.1149/1.1856988

[77] Trasatti, S. Work Function, Electronegativity, and Electrochemical Behaviour of Metals: III. Electrolytic Hydrogen Evolution in Acid Solutions. J. Electroanal. Chem. Interf. Chem. 1972, 39, 163-184. https://doi.org/10.1016/S0022-0728(72)80485-6
[78] Tang, M.H.; Hahn, C.; Klobuchar, A.J.; Ng, J.W.D.; Wellendorff, J.; Bligaard, T.; Jaramillo, T.F. Nickel-Silver Alloy Electrocatalysts for Hydrogen Evolution and Oxidation in an Alkaline Electrolyte. Phys. Chem. Chem. Phys. 2014, 16, 1925019257. https://doi.org/10.1039/c4cp01385a

[79] Zhou, Y.; Chen, W.; Cui, P.; Zeng, J.; Lin, Z.; Kaxiras, E.; Zhang, Z. Enhancing the Hydrogen Activation Reactivity of Nonprecious Metal Substrates via Confined Catalysis Underneath Graphene. Nano Lett. 2016, 16, 6058-6063.

https://doi.org/10.1021/acs.nanolett.6b02052

[80] Oshchepkov, A.G.; Bonnefont, A.; Saveleva, V.A.;

Papaefthimiou,V.; Zafeiratos, S.; Pronkin, S.N.; Parmon, V.N.; Savinova, E.R. Exploring the Influence of the Nickel Oxide Species on the Kinetics of Hydrogen Electrode Reactions in Alkaline Media. Top. Catal. 2016, 59, 1319-1331. https://doi.org/10.1007/s11244016-0657-0

[81] Banik, S.; Mahajan, A.; Bhattacharya, S.K. Size Control Synthesis of Pure Ni Nanoparticles and Anodic-Oxidation of Butan1-ol in Alkali. Mater. Chem. Phys. 2019, 235, 121747.

https://doi.org/10.1016/j.matchemphys.2019.121747

[82] Guo, X.; Liang, T.; Zhang, D.; Zhang, M.; Lin, Y.; Lai, C. Facile Fabrication of 3D Porous Nickel Networks for ElectroOxidation of Methanol and Ethanol in Alkaline Medium. Mater. Chem. Phys. 2019, 221, 390-396.

https://doi.org/10.1016/j.matchemphys.2018.09.066

[83] Martins, R.; Quinello, L.; Souza, G.; Marques, M.

Polymerization of Ethylene with Catalyst Mixture in the Presence of Chain Shuttling Agent. Chem. Chem. Technol. 2012, 6, 153-162. https://doi.org/10.23939/chcht06.02.153

[84] Rocha, L.F.; Ferreira, L.C.; Marques, M.F. Synthesis and Evaluation of Arylimino Pyridine Nickel(II) Catalysts: Influence of Substituents on Polyethylene Structure. Chem. Chem. Technol. 2015, 9, 421-428. https://doi.org/10.23939/chcht09.04.421

[85] Korchuganova, O.; Tantsiura, E.; Ozheredova, M.; Afonina, I. The Non-Sodium Nickel Hydroxycarbonate for Nanosized Catalysts. Chem. Chem. Technol. 2020, 14, 7-13.

https://doi.org/10.23939/chcht14.01.007

[86] Patrylak, L.; Krylova, M.; Pertko, O.; Voloshyna, Y.;

Yakovenko, A. n-Hexane Isomerization Over Nickel-Containing

Mordenite Zeolite. Chem. Chem. Technol. 2020, 14, 234-238.

https://doi.org/10.23939/chcht14.02.234

[87] Manukyan, K.V.; Yeghishyan, A.V.; Danghyan, V.;

Rouvimov, S.; Mukasyan, A.S.; Wolf, E.E. Structural

Transformations of Highly Porous Nickel Catalysts During Ethanol Conversion Towards Hydrogen. Int. J. Hydrog. Energy 2018, 43, 13225-13236. https://doi.org/10.1016/j.jihydene.2018.04.242

[88] Shafiq, Z.; Ajmal, M.; Kiran, S.; Zulfiqar, S.; Yasmeen, G.; Iqbal, M.; Farooqi, Z.H.; Ahmad, Z.; Sahiner, N.; Mahmood, K. et al. Facile Synthesis of Hydrogel-Nickel Nanoparticle Composites and their Applications in Adsorption and Catalysis. Pure Appl. Chem. 2019, 91, 1567-1582. https://doi.org/10.1515/pac-2018-1201 [89] Ignatovich, Zh.V.; Ermolinskaya, A.L.; Katok Ya.M.; Koroleva, E.V.; Eremin, A.N.; Agabekov, V.E. Catalytic Activity of Nickel Nanoparticles in the Reaction of Reduction of Nitroarenes.

Russ. J. G. Chem. 2018, 88, 410-417.

https://doi.org/10.1134/S1070363218030064

[90] Brož, P.; Hejduková, M.; Vykoukal, V.; Zelenka, F.; Sopoušek, J.; Buršík, J.; Zobač, O. Study of Surface Effects and Catalytic Properties of Selected Ni-Based Bimetallic Nanoparticles by Knudsen Effusion Mass Spectrometry. Calphad 2019, 64, 334-341. https://doi.org/10.1016/j.calphad.2019.01.013 
[91] Tada, S.; Ikeda, S.; Shimoda, N.; Honma, T.; Takahashi, M.; Nariyuki, A.; Satokawa, S. Sponge Ni Catalyst with High Activity in $\mathrm{CO}_{2}$ Methanation. Int. J. Hydrog. Energy 2017, 42, 30126-30134. https://doi.org/10.1016/j.ijhydene.2017.10.138

[92] Paul, W.; Sharma, C. Inorganic Nanoparticles for Targeted Drug Delivery. In Biointegration of Medical Implant Materials. 2nd ed.; Sharma, C.P., Ed.; Woodhead Publishing Series in Biomaterials: Oxford, 2020, pp 333-373.

[93] Hidaka, S.; Okamoto, Y.; Abe, K. Elutions of Metal Ions from Dental Casting Alloys and their Effect on Calcium Phosphate Precipitation and Transformation. J. Biomed. Mater. Res. 1994, 28, 175-180. https://doi.org/10.1002/jbm.820280206

[94] Raison-Peyron, N., Guillard, O., Khalil, Z.; Guilhou, J.-J.; Guillot, B. Nickel-Elicited Systemic Contact Dermatitis from a Peripheral Intravenous Catheter. Contact Derm. 2005, 53, 222-225. https://doi.org/10.1111/j.0105-1873.2005.00689.x

[95] Nosbaum, A.; Rival-Tringali, A.L.; Barth, X.; Damon, H.; Vital-Durand, D.; Claudy, A.; Faure, M. Nickel-Induced Systemic Allergic Dermatitis from a Sacral Neurostimulator. Contact Derm. 2008, 59, 319-320. https://doi.org/10.1111/j.1600-0536.2008.01434.x

[96] Memon, A.A.; Molokhia, M.M.; Friedmann, P.S. The Inhibitory Effects of Topical Chelating Agents and Antioxidants on Nickel-Induced Hypersensitivity Reactions. J. Am. Acad. Dermatol. 1994, 30, 560-565.

https://doi.org/10.1016/s0190-9622(94)70062-1

[97] Wöhrl, S.; Kriechbaumer, N.; Hemmer, W.; Focke, M.; Brannath, W.; Götz, M.; Jarisch, R. A Cream Containing the Chelator DTPA (Diethylenetriaminepenta-Acetic Acid) Can Prevent Contact Allergic Reactions to Metals. Contact Derm. 2001, 44, 224-228. https://doi.org/10.1034/j.1600-0536.2001.044004224.x

[98] Vemula, P.K.; Anderson, R.R.; Karp, J.M. Nanoparticles Reduce Nickel Allergy by Capturing Metal Ions. Nat. nanotechnol. 2011, 6, 291-295. https://doi.org/10.1038/nnano.2011.37
[99] Mo, Y.; Jiang, M.; Zhang, Y.; Wan, R.; Li, J.; Zhong, C.-J.; Li, H.; Tang, S.; Zhang, Q. Comparative Mouse Lung Injury by Nickel Nanoparticles with Differential Surface Modification. $J$.

Nanobiotechnology 2019, 17, 1.

https://doi.org/10.1186/s12951-018-0436-0

[100] Wang, C.-J.; Chen, T.-C.; Lin, J.-H.; Huang, P.-R.; Tsai, H.-J., Chen, C.-S. One-Step Preparation of Hydrophilic Carbon Nanofiber Containing Magnetic Ni Nanoparticles Materials and their Application in Drug Delivery. J. Colloid Interface Sci. 2015, 440, 179-188. https://doi.org/10.1016/j.jcis.2014.10.073

[101] Gonçalves, A.A.; Araújo, A.F.; de Mesquita, J.P.; Pires, M.J.M.; Verly, R.M.; Da Silva, L.M.; Franco, D.V. Characterisation of Silica-Supported Fe-Ni Bimetallic Nanoparticles and Kinetic Study of Reductive Degradation of the Drug Nimesulide. $J$. Environ. Chem. Eng. 2016, 4, 4354-4365. https://doi.org/10.1016/j.jece.2016.09.038

Received: September 25, 2020 / Revised: October 12, 2020 / Accepted: February 15, 2021

\section{НАНОТЕХНОЛОГІЇ ПРИГОТУВАННЯ ТА ВИКОРИСТАННЯ МЕТАЛІЧНОГО НІКЕЛЮ}

Анотація. Наноструктурований нікель має значну площу поверхні на одиницю об'єму та керовані оптичні, електронні, магнітні та біологічні властивості, щчо робить наноприготування нікелю надзвичайно привабливим з точки зору його практичного застосування у різних галузях хімії. В роботі узагальнено технології по наноматеріалах нікелю, включаючи їх просте приготування та сучасне застосування.

Ключові слова: наноструктурований нікель, наноприготування металу, магніт, колектор струму, каталізатор, доставка ліків. 